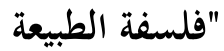 \\ عند أرسطو" \\ Philosophy of natural \\ at Aristotle \\ د.محمّد حسين محجوب \\ جامعة بنغازي/ كلية الآداب \\ Face Book.Elghiran.
}

\section{ملخص البحث.}

يحاول هذا البحث، أن يدلل عن الفرضية الجوهرية ؛ التي نصها: أن جلّ القراءات التي قدمت الته

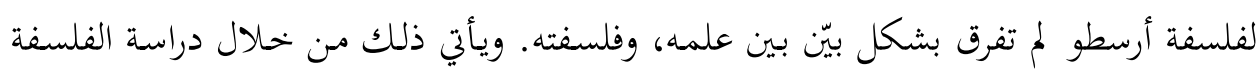
الطبيعية التي أسسها، كما أسس علم المنطق، وكما وضع الخطوط العريضة لفكرة النقد الأدبي.

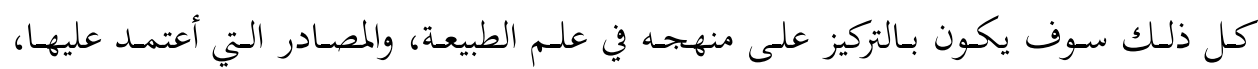
والنظريات التي قدمها في علم البيولوجيا.

Abstract.

This research study tries to demonstrate the fundamental premise that most readings of Aristotle's philosophy did not distinguish between his SCIENCE and his philosophy. This comes through the study of the natural philosophy that he founded AND the foundations of logic, as well as the outline of the idea of literary criticism. All this will be focused on THROUGH his approach to the science of nature, the sources on which he relied, and his theories in biology. 
فكرة البحث Search idea.

يُعـد أرسطو في جـلّ القراءات، أو أغلبها على الأقل؛ فيلسوفاً؛ صـاحب مـذهب، ومدرسـة

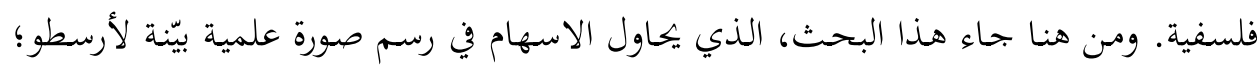
تعادل وربما تتجاوز صورته الفلسفية. فرضية البحث Search hypothesis

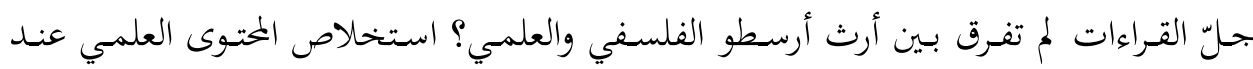

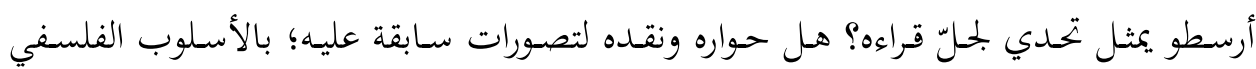

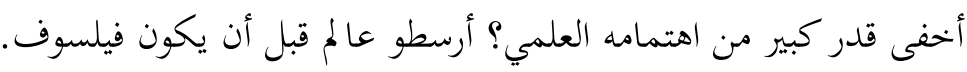

هدف البحث Research goa.

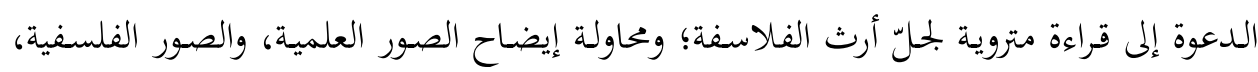

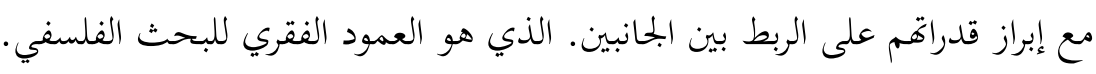
المقدمة Introduction

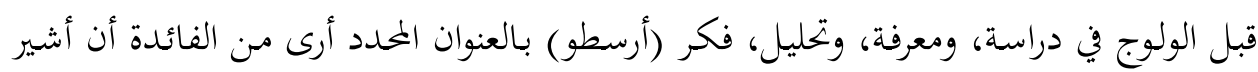

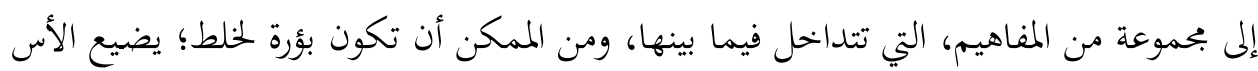

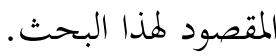

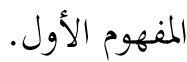

\section{فلسفة الحياة Philosophy of Life}

تشير المعاجم الفلسفية إلى أن هذا المفهوم يعني " ابتحاه مثلالي ذاتي في الفلسفة نشأ في المانيا في

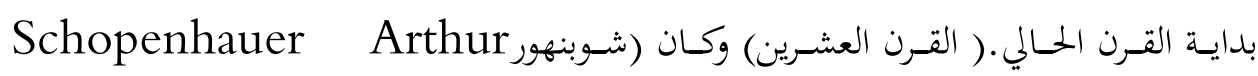

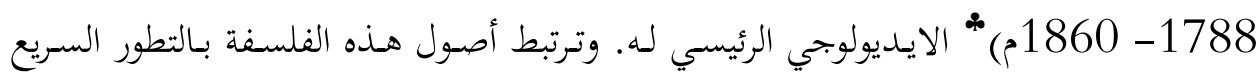

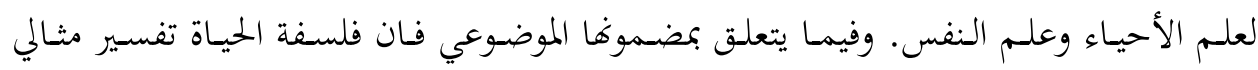


محرف للعملية التاريخية الاجتماعية ـ وذروة هذه الفلسفة هو مفهوم الحياة باعتبارها المبدأ المطلق اللانهائي للعلم. وبداخلها بجموعتين أساسيتين:

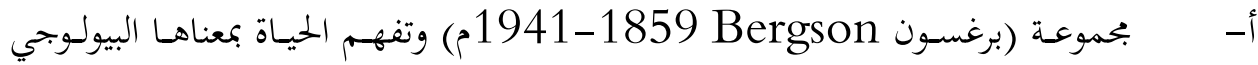
وتمد نطاق الصفات البيولوجية لتشمل الواقع كله.

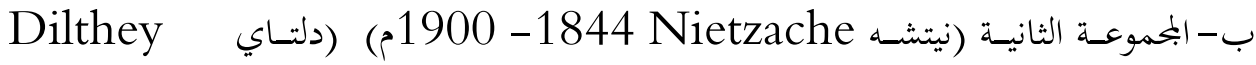
1833- 1911م) • وتتصور الحياة على أها الإرادة العاطفية الداخلية أو العرض اللاعقلاني للقوى الروحية" م. روزنتال، ب يودين" الموسوعة الفلسفية" ص 340 وعند شوبنهور فإن إن إرادة الحياة Will to Live" جهد غريزي يحقق به كل كائن نموذج نوعه، ويناضل الكائنات الأخرى للحفاظ على صورة الحياة التي توافرت لديه، وهي غريزة أصيلة راسخة في الإنسان،

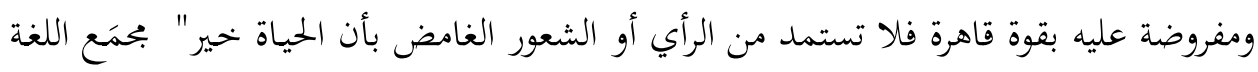

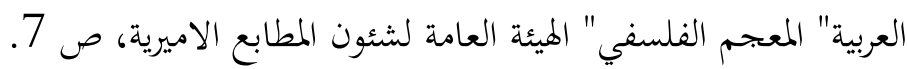
المفهوم الثاني.

\section{البيولوجية Biology}

ويقصد بهـذا المصطلح" تلك العلوم التي تتعامل مع جميع الكائنـات الحية مـن إنسـان ونبـات وحيـوان مـن النـواحي التشـيكية و الوظيفيـة والوراثيـة والبيئيـة والتطوريـة وتنـدرج صـحة الإنسـان

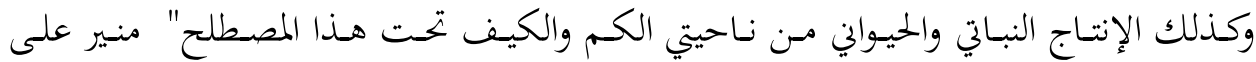
الجنزوري " نحن والعلوم البيولوجية" الجزء الأول ص 11 ويقول علماء البيولوجيا " البيولوجيا :

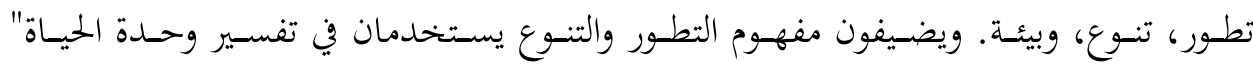
كما يعرف بالقول "علم الاحياء أو Sylvia S. Mader " biology" p. xvii البيولوجيا بالإبحليزية: Biology (من اليونانية، Bios حياة و Logos ملم) هو علم دراسة

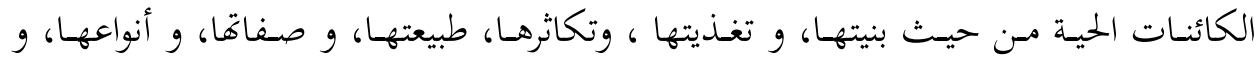
القوانين التي تحكم طرق عيشها و تطورها و تفاعلها مع وسطها الطبيعي. و علم الاحياء واسع 
جدا و ينقسم لعدة فروع من أهمها علم الكائنات البمهرية و علم الحيوان و علم النبات و كذلك علم وظائف الاعضاء والكيمياء الحيوية و علم البيئة. لا شك أن هذا المفهوم يحمل مـ التقدم العلمي ما لم يكن موجود زمن أرسطو وعليه فهو أوسع من نطاق هذا البحث.

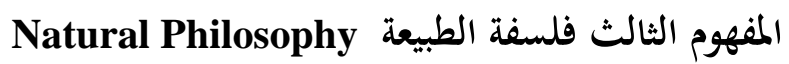

وهو الاسم الذي أطلق على الفلسفة التي تقوم على تفسير تأملي للطبيعة. وأكدت "

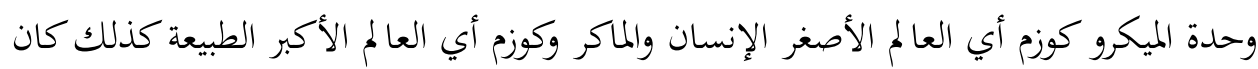

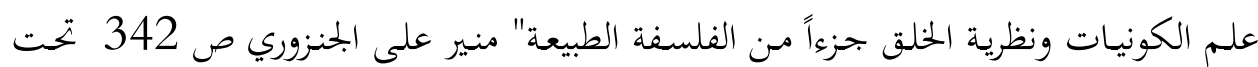

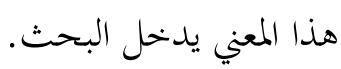
عندما يذكر ( أرسطو 3ristotle

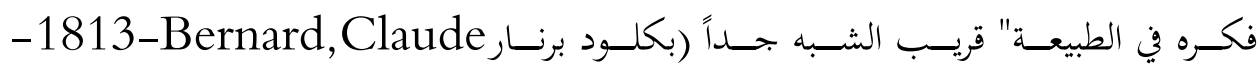

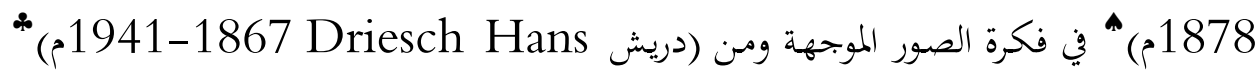
الذي يقول بوجود الصورة الغائية Teleology في الكائن الحي فإن هـا يضع أرسطو في مصاف العلماء في زمنه ويلبسه حلة الاستشراف. وهو القائل " قد قيل مـا ذكر القـدماء مما

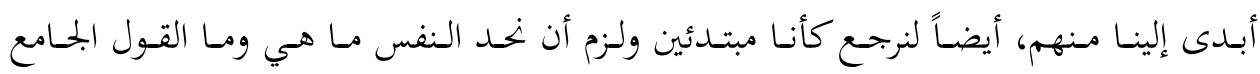
المستفيض منها" أرسطو طاليس "كتاب النفس" ص 34 ولكن هذا لا يعني أن أرسطو قدم

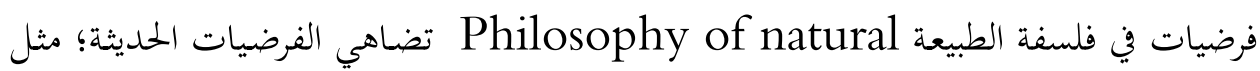
فرضية نشوء الحياة التي يقول عنها العلماء في هذا العصر" من البديهي عندما يُبحث في موضوع

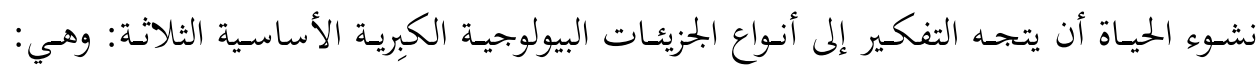

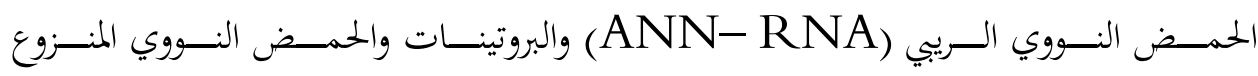
الأكسجين(ADN DNA) وليس إلى أي مادة أخرى من مئات المواد التي تحويها الخلية؛

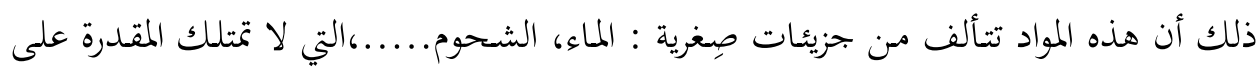

• فيلسوف وعالم فرنسي صاحب كتاب مدخل لدراسة الطب التجريبي. * عالم بيولوجي الماني وفيلسوف ومؤسس المذهب الحيوي الجديد. 
اختزان المعلومات الضرورية لتكوين أجيال لاحقة" هـاني رزق" موجز تاريخ الكون" ، ص 232

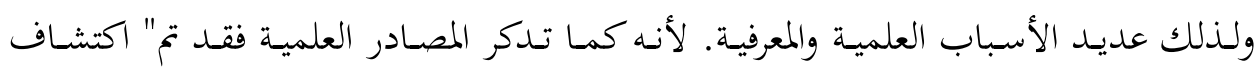
الأمماض النووية سنة 1871م وفي عام 1951م كشف لأول مرة تتابع الأمـاض الأمينية في أحسد البروتينـات" منير على الجنزوري" نحن والعلوم البيولوجيـة" ، ص 53 و بذكر(أرسطو) يـذكر مـذهب فلسـفي Philosophical Doctrine وبمعـنى اصـح تـذكر مدرسـة

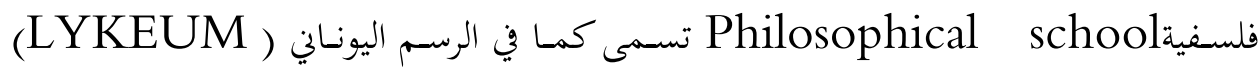
"وقد عربها القدماء فقالوا اللوقيون" وهي المدرسة التي أنشاها (أرسطو) في أثينـا

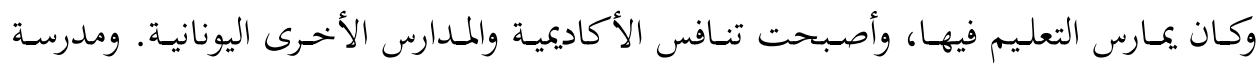

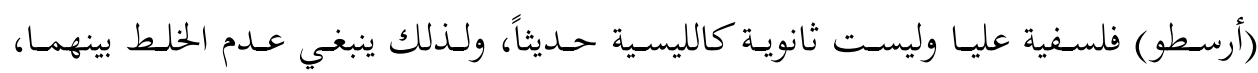

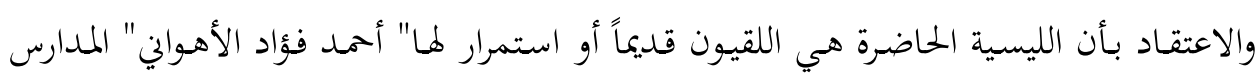

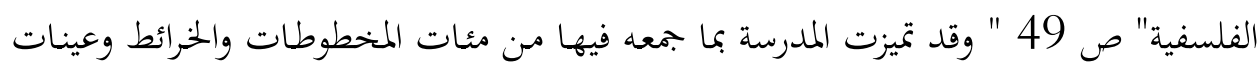

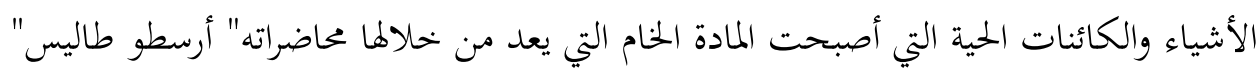

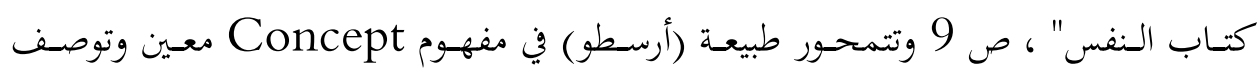

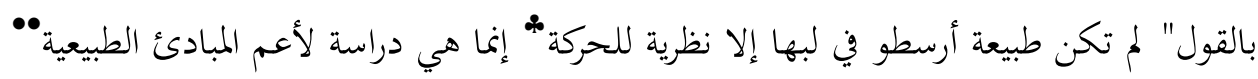

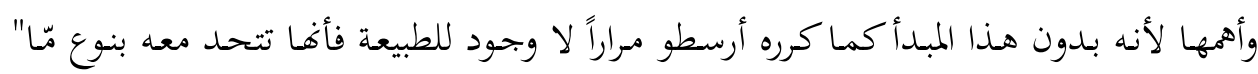

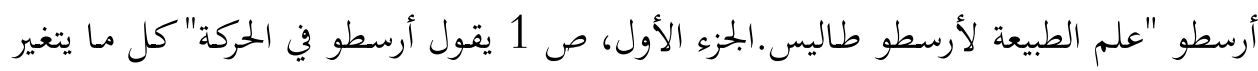

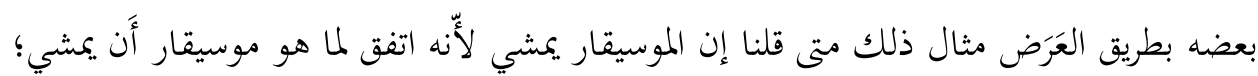

• وتعرف مدرسة أرسطو باسم آخر وبخاصة عند العرب هي مدرسة المشائين لأن المعلم وتلاميذه كانوا يتعلمون وهم يمشون. * تطور هذا لمفهوم وفي نهاية القرن السابع عشر إذ يضع نيوتن المبادئ الرياضية للفلسفة الطبيعية وإذ يوضح نظام

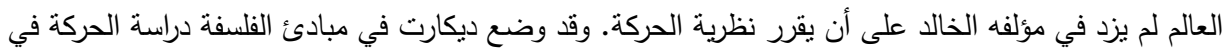

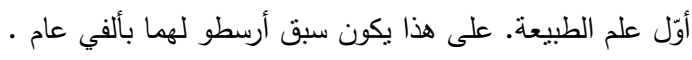

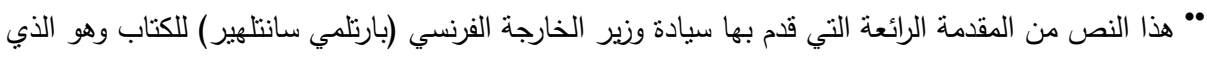

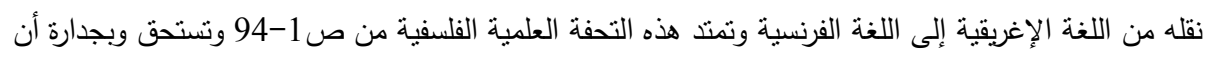
تكون كتاباً بكل ما تعني الكلمة. 
وبَعْضُه لأَن جزءاً منه يتغير يقال على الإطلاق إنه قد تَغيَّر، مثال ذلك ما يقال بحسب حال

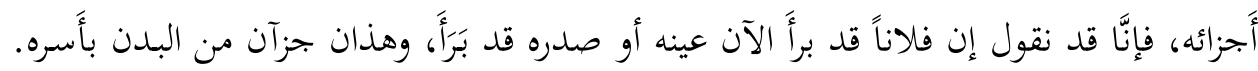

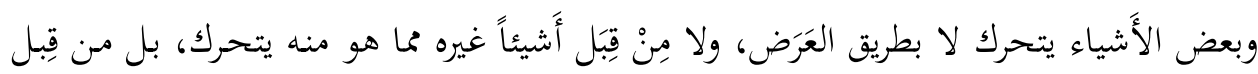

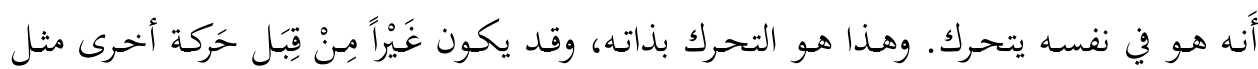

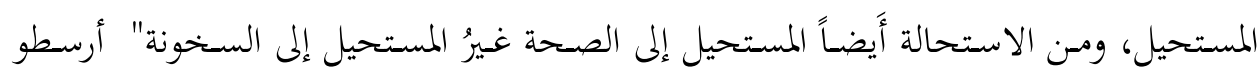

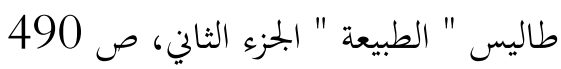
والسؤال الآن ما هو موضوع (علم الطبيعة - فلسفة الطبيعة) عند أرسطو. موضوع فلسفة الطبيعة Subject of Natural Philosophy. فلسفة الطبيعة هو " الاسم الذي أطلق على الفلسفة التي تتميز بتفسير تأملي سائد للطبيعة مأخوذة في كليتها. ففي العصور القديمة كانت الفلسفة الطبيعية متزجة بالعلم الطبيعي وكانت تسمى في الفلسفة اليونانية عادة بالفيزيقا ـ وكان لعناصر من الفلسفة الطبيعية وجود حتى في

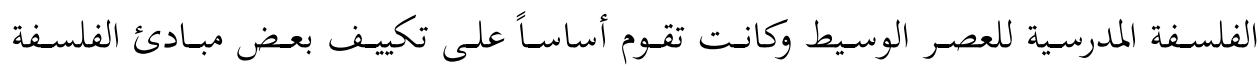

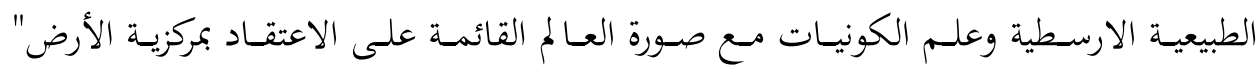

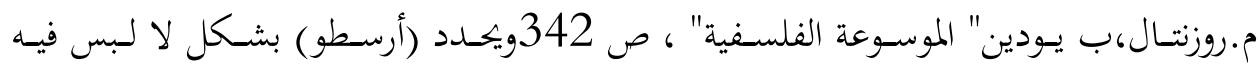
موضوع فلسفة الطبيعة مـن خهلال النص التالي: " الطبيعة هي التي تكوّن الحيوانات والأجزاء المختلفة المركبة منها أجسامها لأننا نقول على هذه الأشياء وعلى جميع تلك التي تشابهها إنه توجد بعمل الطبيعة وحده. كل الكائنات الطبيعية تحمل في أنفسها مبدأ حركتها وسكونها سواء

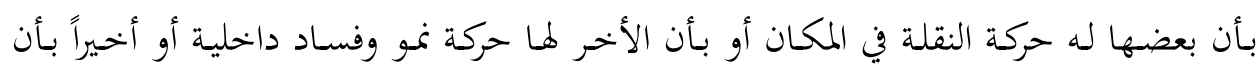

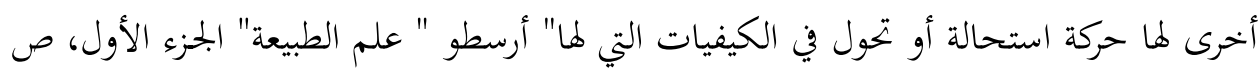

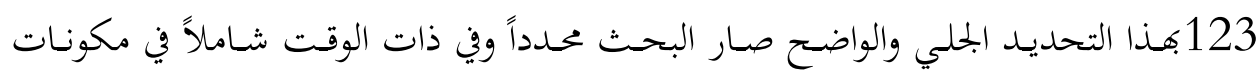
الكون التي تنتجها الطبيعة، بمعني يشمل النبات، والحيوان، والإنسان، وهي ذاتما موضوع البحث إنح

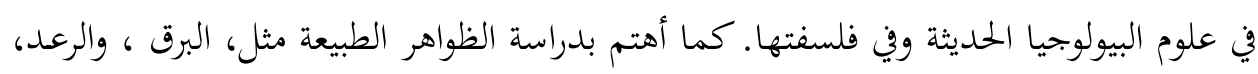
وكذلك الصواعق تشير بعض المراجع العلمية إلى هذا بالقول" لقد كان من ضمن فلسفة أرسطو 
طاليس الطبيعة دراسة الأحوال الجوية وبحسد ذلك في كتابه الآثار العلوية وسوف نستعرض فيما

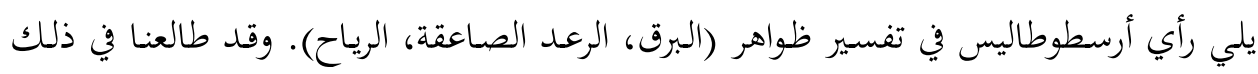
مصدرين: الأول. هو كتاب تفسير ألمفيدوروس للآثار العلوية عند أرسطوطاليس. والثاني - كتاب أرسطوطاليس نفسه في السماء والآثار العلوية. البرق - الرعد - الصاعقة: في كتاب أرسطوطاليس"في السماء والآثار العلوية" بحد أنه ينتقد رأي من سبقه من علماء اليونان ومنهم أنكساغورس Anaxagoras الذي يقول: "إن البرق

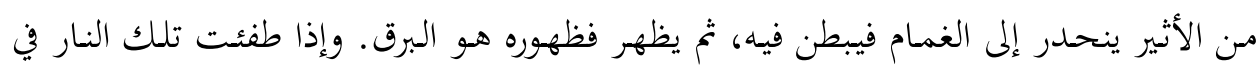
السحاب كان صوت ذلك الإطفاء هو الرعد" لقد أنكر أرسطوطاليس تلك الآراء وقال إن مادة

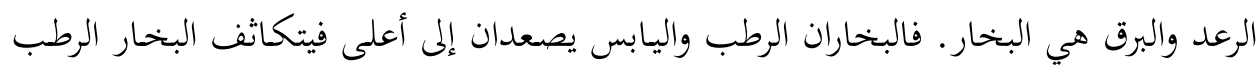

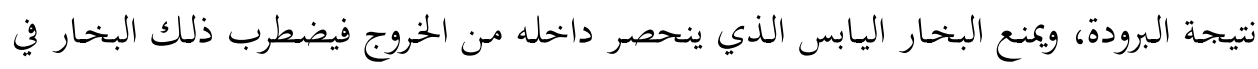
الداخل، ويندفع من الجهة العليا من السحاب وهي الجهة الأكثر برودة، إلى الجهة السفلى الأقل برودة، ونتيجة هذا الاندفاع يحدث صوت الرعد مع طلب البخار النفاذ. وبعد الاندفاع يمكن

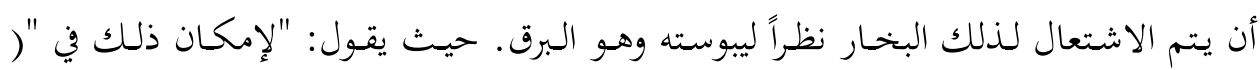

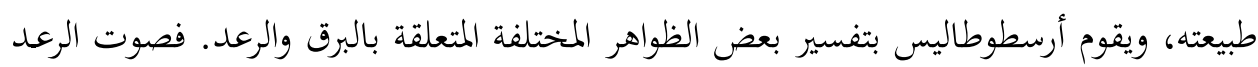

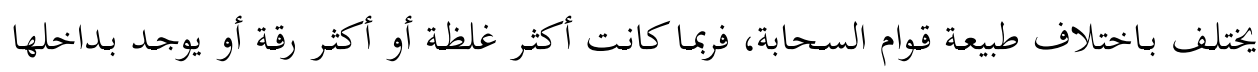

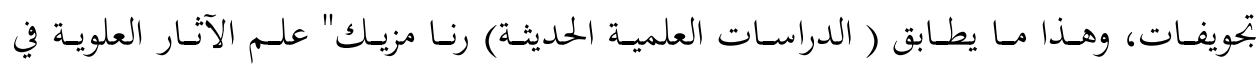

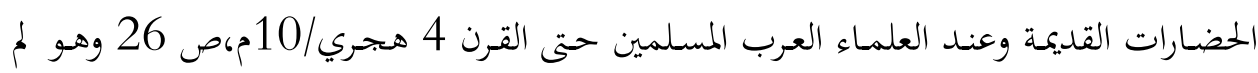
يطرح مسألة أصل الحياة. لأن التفكير في هذه المسألة على ما يقول العلماء يحتاج معلومات ربما لم تكن عند أرسطو ولا غيره من علماء ذلك العصر وكذلك لم يطرح فكرة بداية الحياة. والسؤال

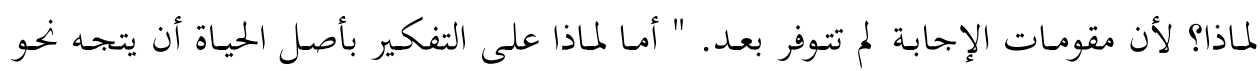

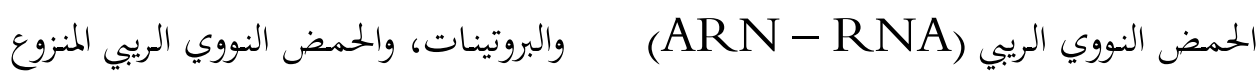
الأكسجين ( ADN -DNA ) فذلك لأن هذه الجزيئات قادرة على التوالد " الاستقلاب

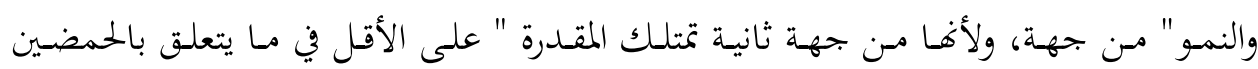


النووين ADN، DNA, ARN، RNA" على الختزان المعلومات " الذاكرة الجينية" التي تمكنها من توليد أجيال قادمة" هاني رزق" موجز تاريخ الكون" ص 232. وتتضح الصورة الكالئ

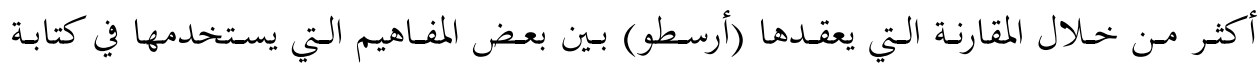

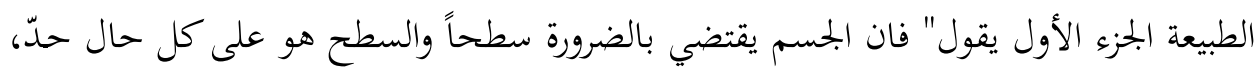

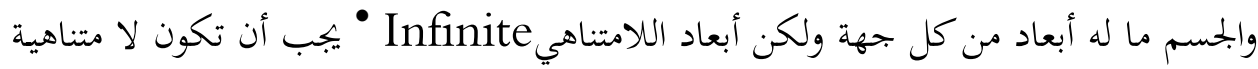

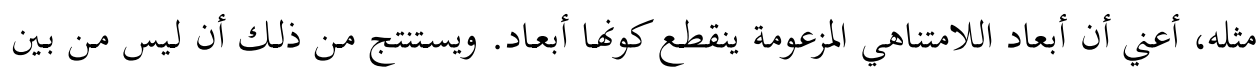

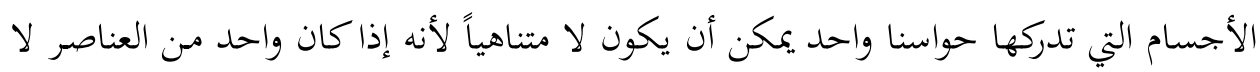

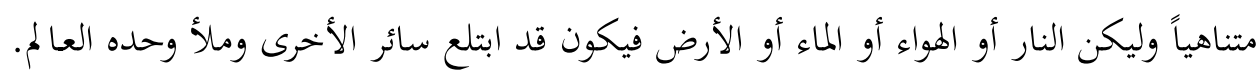

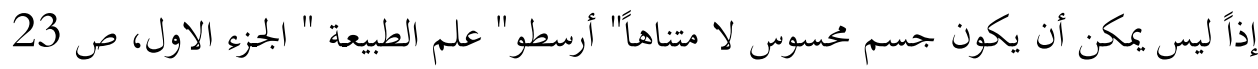

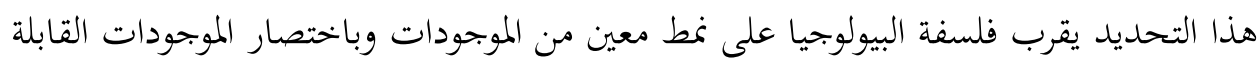
للفحص والتجريب والغير مصنوعة بفعل البشر ابتدأ.

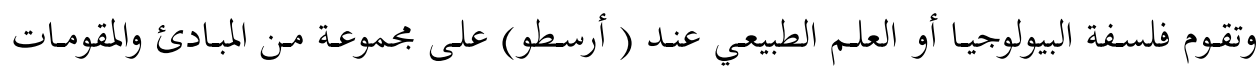
وهي: 1- المبدأ الأول: يقول أن في الطبيعة أشياء تتحرك. هذا حدث يعلمنا إياه الاحساس بالبداهة التامة والاستقراء يقرّهّ بمجرّد التفكير فيه

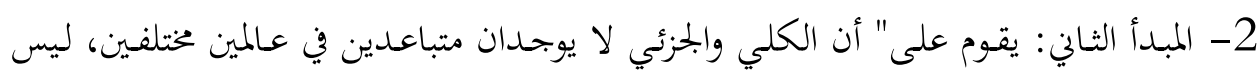

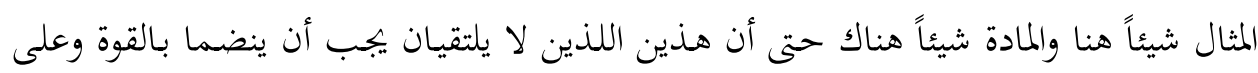

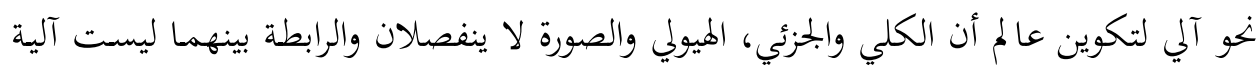

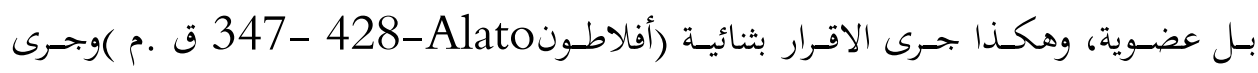

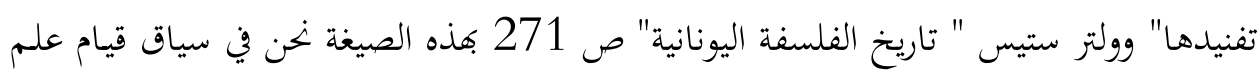

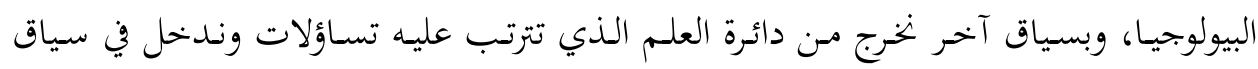

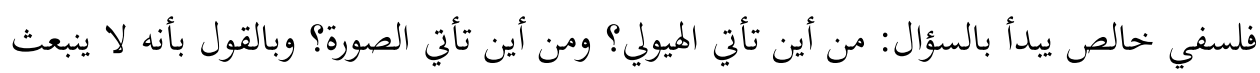
• اللامتناهي هو بطبعه غير قابل لأن يقاس كما في الصوت هو بالطبع غير قابل لأن يرى. 
أحدها من الآخر نصل إلى نتيجة شبه حاسمة وهي أنه لا يمكن تفسير العالم. هنا نلاحظ أن الفيصل بين العلم والفلسفة السؤال وطبيعته. 3- المبدأ الثالث: مبدأ الغائية Teleology حيث يرى أرسطو أنه مبدأ اساسي في الطبيعة.

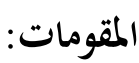

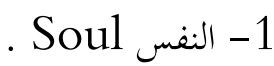

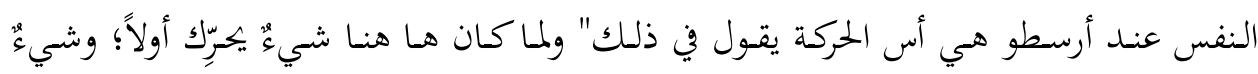

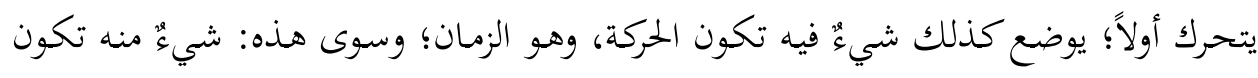

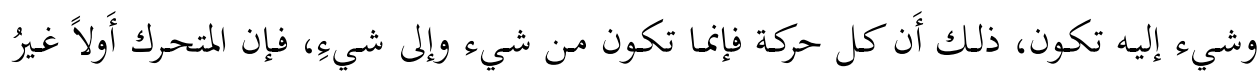

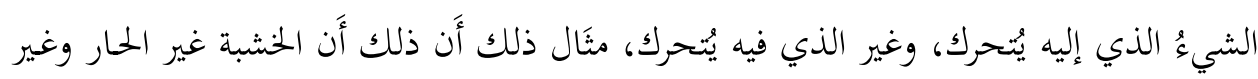

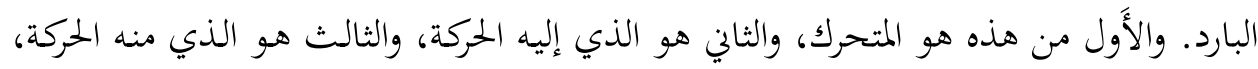

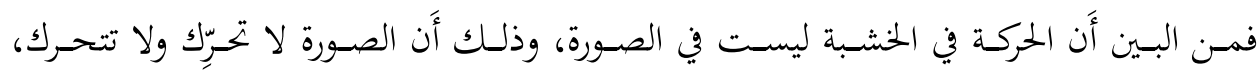

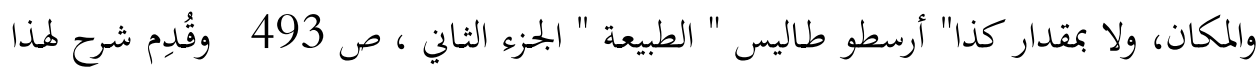

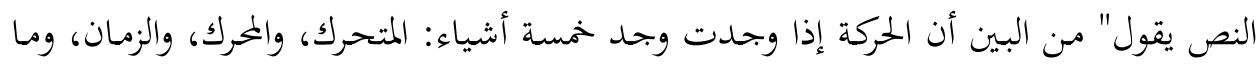

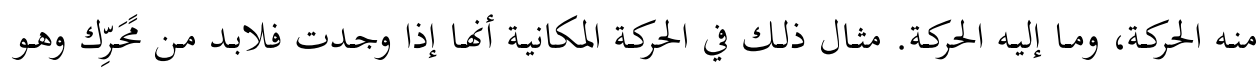
النفس ولابد من متحرك وهو البدن ولابد من زمان فيه تكون الحركة ولابد من مكان منه تبتدئ

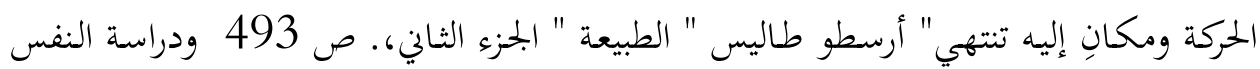

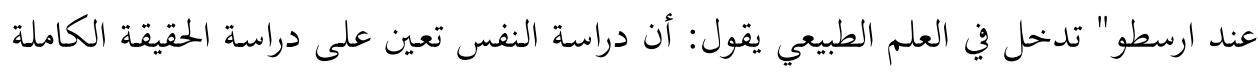

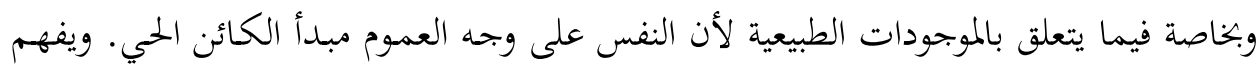

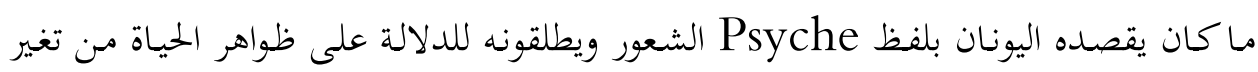

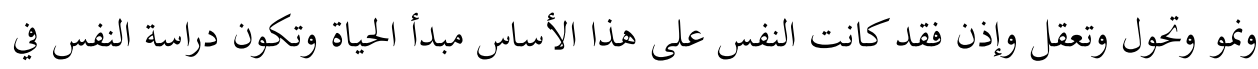

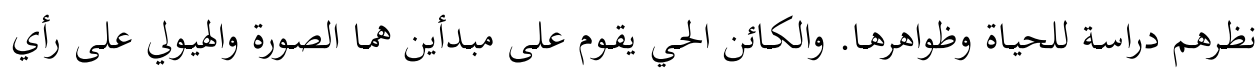

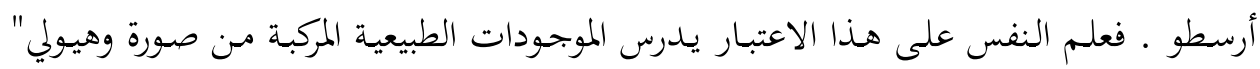

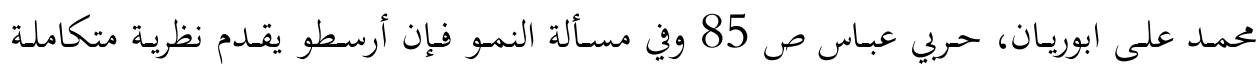


منها" في شيء ينمو يظهر إذا أن جميع الأجزاء بلا استناء تنمو؛ كما أنه في النقصّ جميع أجزاء الشيء يظهر أهـا تصير أكثر فأكثر صغيرة. وفوق ذلك فان النمو يظهر أنه يجصل بأن شيئاً

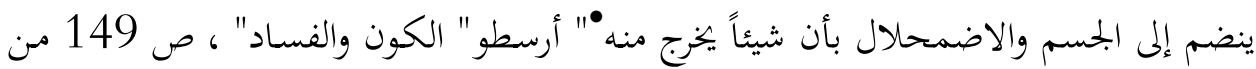
المفيد أن أشير هنا إلى أن تصور النفس وبقائها في الجسد يختلف بئف بين (أفلاطون) و (أرسطو) عند (أفلاطون) مـن الممكـن أن تغادر النفس الجسـد وعند (أرسطو) النفس مرتبطة بالجسـد ويحدد

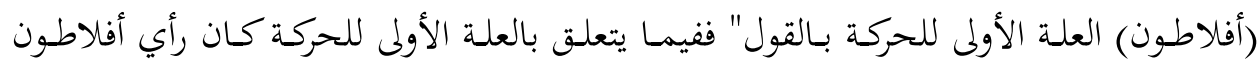
جازما جهد الامكان ولم يكن ليتردّد في أن يسند إلى الله الحركة التي تظهر في كل مكان في العالم والتي تؤتيه الحياة ـ انما الله هو الذي استخرج من أعماق وجوده الحركة والذي بثها في سائر

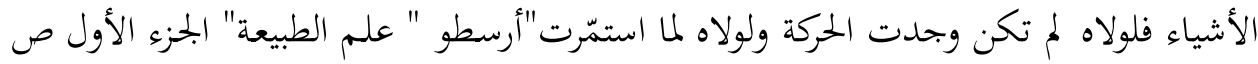

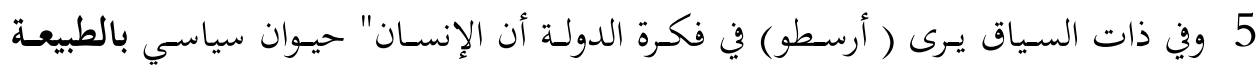
وبرهان هذا امتلاكه للحديث الذي يكون بلا قيمة الا لكائن اجتماعي وتعبير بالطبيعة يعني هنا نفس المعنى الذي في جميع فلسفة أرسطو وهو يعني أن الدولة هي غاية الفرد وأن النشاط في برهي

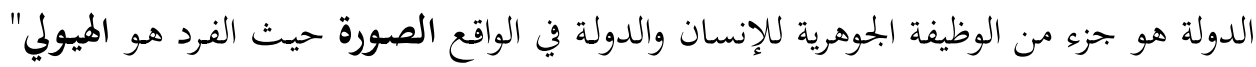
وولتر ستيس" تاريخ الفلسفة اليونانية" ص 262 أينما يوجد التفاعل يوجد الهيولي والصورة.

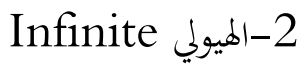
Imagea 3

\section{فلسفة أرسطو الطبيعية Aristotle's natural philosophy}

تقول المراجع الفلسفية أن " موضوع الفلسفة الطبيعية أو العلم الطبيعي عند أرسطو هو دراسة

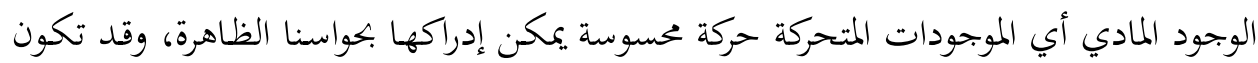

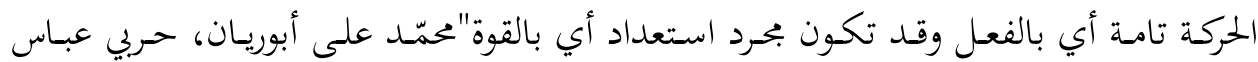
عطيتو" دراسات في الفلسفة القديمة والعصور الوسطص 35 وفي هذه النقطة لابأس من ذكر لحري

• قد يعد هذا التصور دعوة إلى علم البيولوجيا اليوم لدراسة أسباب الثيخوخة ومحاولة تحديد تضاءل جسم الإنسان في حال نقدمه في العمر. 
تصور لأستاذ أرسطو" هناك قاعدة لم يتغير رأيه فيها كما لم يتغير في منشأ الحركة وتلك القاعدة هي أنه لا شيء البتـة مـ المصادفة في الطبيعة وأن الحركة التي هي ظاهرتها الرئيسية لها فيها

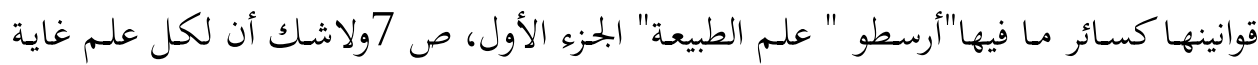

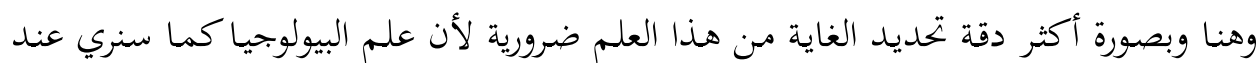
(أرسطو) يهدف إلى غاية يحددها في النشاط الكوني فيما يخص الكائنات الحية بذاتما والكون كله وفقاً لغاية شاملة. وقد أهتم (أرسطو) بدراسة مفهوم الحياة The concept of life التي

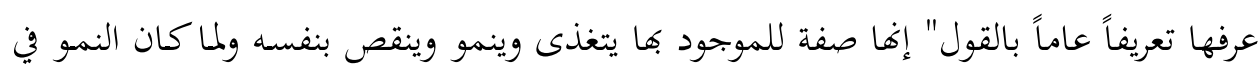
الواقع يقتضي الاستحالة فيمكن ارجاع الصفة الرئيسية للحياة إلى فكرة التغذي بالذات ولهذا

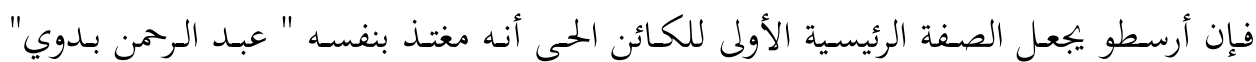

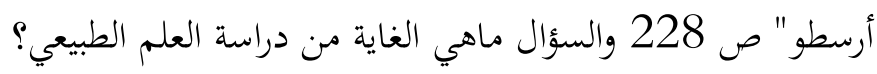

الغاية في فلسفة الطبيعة The end of the philosophy of nature. غاية فلسفة العلم الطبيعي؛ المعرفة كما يحددها ( أرسطو) في الكتاب الثاني، من كتاب الطبيعة. " أو بمعنى آخر العلم الطبيعي علم نظري غايته تفسير الظواهر الطبيعية تفسيراً عقليا وليس العلم الطبيعي كالأخلاق التي هي علم عملي ولما كانت المعرفة تستهدف اكتشاف العلل

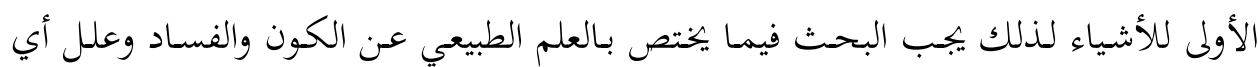
تغير طبيعي، فيدخل إذن في هذا البحث حصرأعداد العلل وأنواعها" محمّد على أبوريان، حربي عبـاس ص 35 وفي فلسفتهه في العلم الطبيعي " يسخر مـن ( أمبيـدقل) الذي تخيـل أن أجزاء الحيوانات يأتلف نظامها العجيب بعضها مع بعض بمجرّد المصادفة وأن الظواهر العلمية ليس لها قوانين فهي تقع تارة على وجه وتارة على آخر. إن الطبيعي الحق متى درس انواع العلل الأربعة اقتنع في سهولة بأن الطبيعة تعمل دائما لغاية ملحوظة ومن أجل أهما منظمة في أكثر الأحوال فهي ليست خاضعة إلى قوّة عمياء فيه إذاً ليست تحت نير الضرورة. على ذلك ليس في الطبيعة مصادفة واتفاق وليس في الطبيعة ضرورة. وعلى هذا فالتشويه في الخلق هو انحراف عن القوانين 
العادية وعن غرض لم يصب انما هو فساد البذر والجرثومة بسبب يبقى بحهولاً عندنا. نكرر عالياً

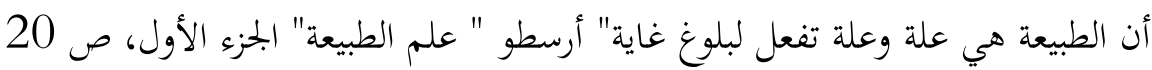

اهتمامه بالعلم الطبيعي يمكن القول بأن اهتمامه بالعلم الطبيعي، والطب، قد وجد منذ الصغر ولوالده في ذلك أثر

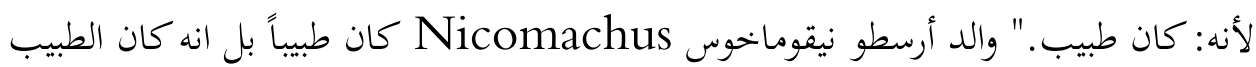

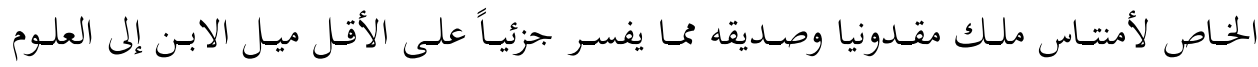

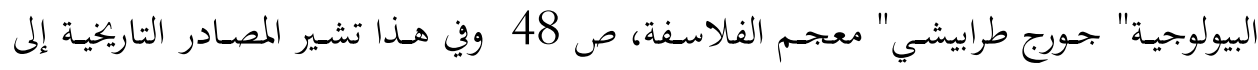
ميراث مهنة الطب في عائلة أرسطو تقول" ولأن مهنة الطب كان يتوارثها أبناء أسرته منذ أجيال بعيدة فقد هيئ الصبي للتدريب على مهنة والده وأجداده، بمعاونة مواهبه على تشرب الروح

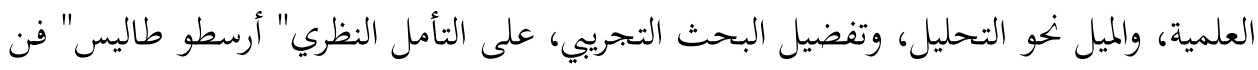
الشعر" ص 15ومسن علامـات هـذا الاهتمـام تصنيفه للكائنـات الحيـة حيـث يقسم (أرسطو)

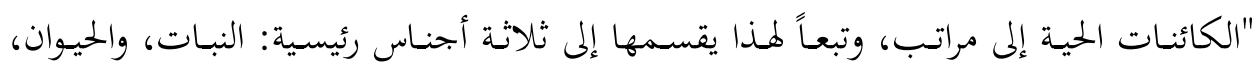

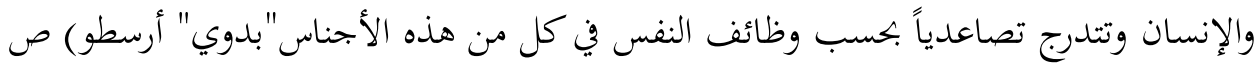
231 والنفس عنده في علاقة جوهرية مع الجسم ولا تنفصل عنه " أنه اتصال جوهري كاتصال الصورة بالمادة إذ أن أرسطو لا يعتبر النفس جوهراً قائماً بذاته ولا الجسم أيضاً جوهراً قائماً بذاته

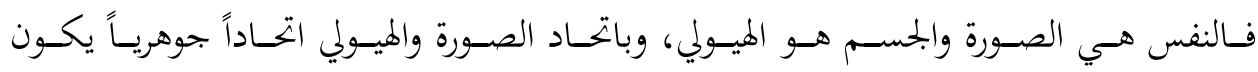
الإنسان"جعفر حسن الشكرجي ص 133 وهذا بعكس رأي (أفلاطون) الذي يرى أن اتصال

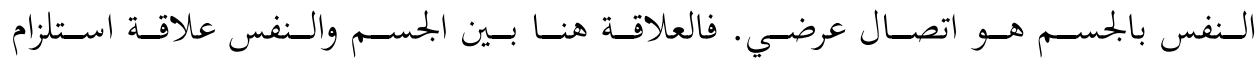
Requirement أنه موجود حقيقي وأنه واحد في الوجود الخارجي ويحاول أن يضع مبادئ يفسر بهـا الأجسام

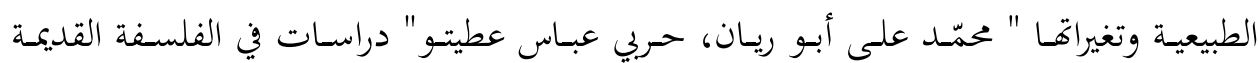
والعصور الوسطى" ص 41 وترجع مباحث أرسطو ومشاهداته في العلم الطبيعي والبيولوجي 
إلى اقامته في أسوس وميتلين " الأهواني (المدارس الفلسفية) ص 53 وياكد ذلك مـ خحلال كتاب النفس لأرسطو حيث يقول" اهتمام أرسطو بالبحث في علم الأحياء والتاريخ الطبيعي يعود إلى تلك الفترة التي قضاها في أترنوس ( أسوس) وميتلين" أرسطو طاليس "كتاب النفس"

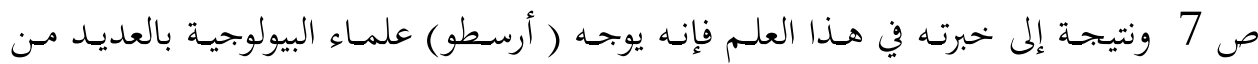

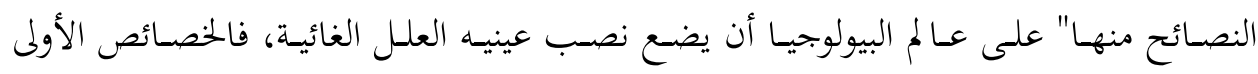

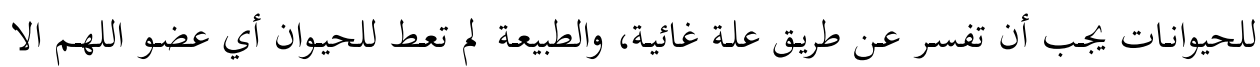

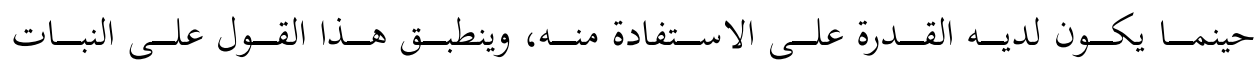
أيضا" Wardman, F.\& Green,J.L,The philosophy of Aristotle pp. 224.225

ويمكن القول بأن اهتمام (أرسطو) بالعلوم الطبيعية والبيولوجيه يعود إلى تصوره العام للفلسفة

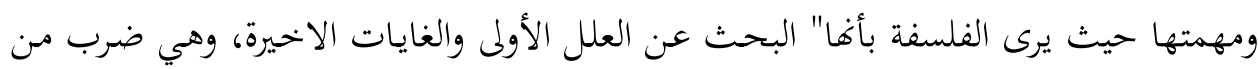

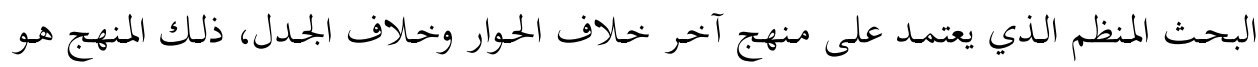
المنطق الذي ابتكره حتى أشتهر به ولقبه المتأخرون وبخاصة العرب صاحب المنطق. فالفلسفة عند المند أرسطو هي العلم بالموجود من حيث هو موجود أي أنه يقر ويعترف بالموجود المحسوس وما دام

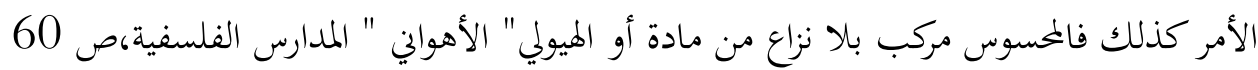
ومن هنا يتضح ابحاه (أرسطو) الفلسفي لأنه أختلف عن ابتحاه الأكاديمية لأن ابحاه (أفلاطون) ومدرسته رياضياً وابتحاه (أرسطو) طبيعياً وفلسفة الطبيعة تبحث في أرسطو) أمور ومواضيع تختلف فيها آنتاه

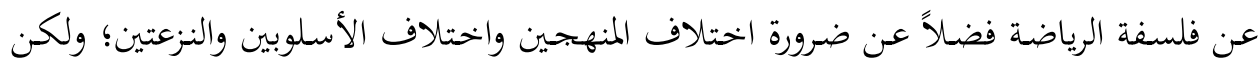

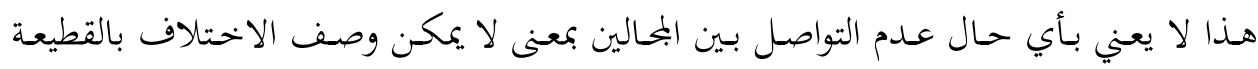
المعرفية.

\section{نظريات أرسطو في البيولوجيا Aristotle's theories in biology.}

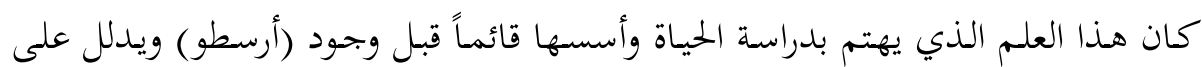
ذلك نظرية ( هيبوقراط أبقراط 377 Hippocrates ق.م) القائلة " أن جزيئات دقيقة من وند 
كل جزء من أجزاء الجسم تدخل المواد المنوية من الآباء التي يتشكل منها الفرد الجديد وبذلك

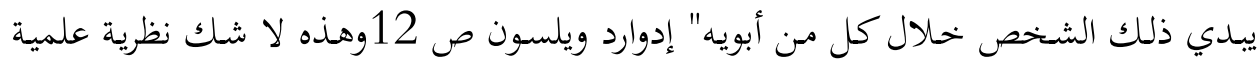

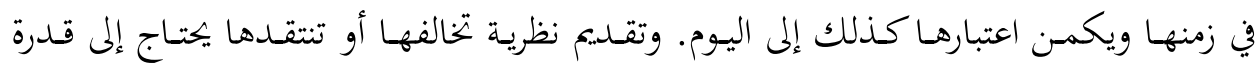
علمية؛ وهنا يصف بعض البحاث مقدرة أرسطو على صياغة العلم وتبدل معانيه عنده بالقول" إن المعاني تتغير صورها تحت يده إذ يطبعها بالطابع العلمي المرتب وبهذه الصورة النهائية التي

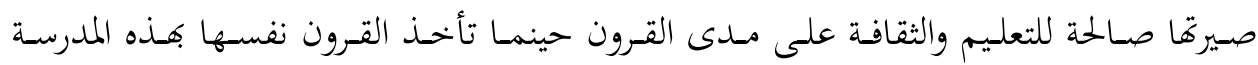

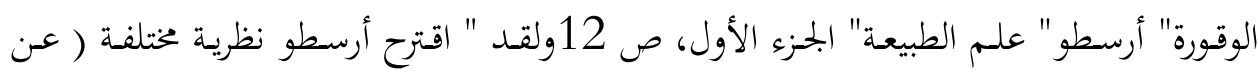

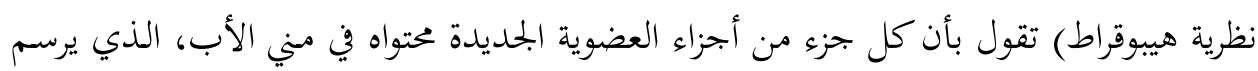

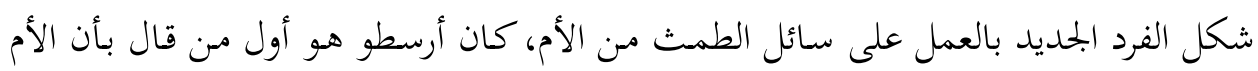

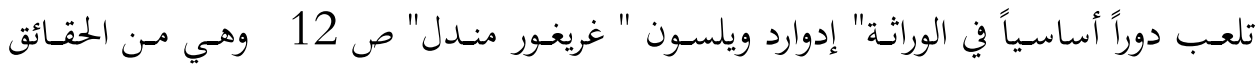

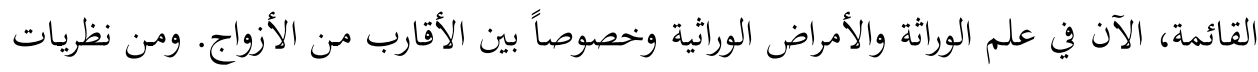

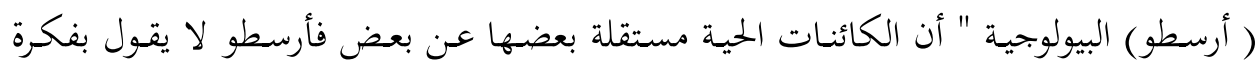

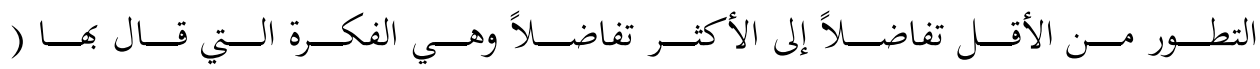
أنبادوقليس 492 Empedocles-430 ق. م ) وإنما يقول بأن الحياة تنشأ في الأغلب وهب

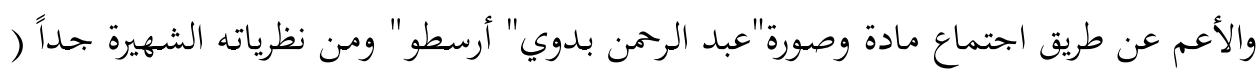
نظرية الهيولي) والتي تقول" أن مبادئ الموجودات هي اثنان بالعدد باعتبارهما من جهة نظون نظر معينة

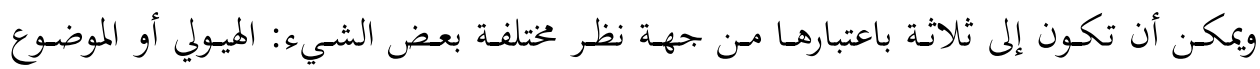
والصورة والعدم" أرسطو" علم الطبيعة" الجزء الأول، ص 15 ويرى بعض الباحثين أن (أرسطو) "كان يقول بمذهب أن كل شيء ذو نفس فيما يتصل بالكائنات الحية على أقل تقدير فمذهبه

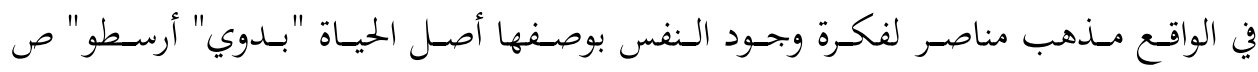

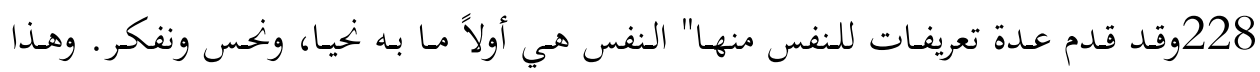

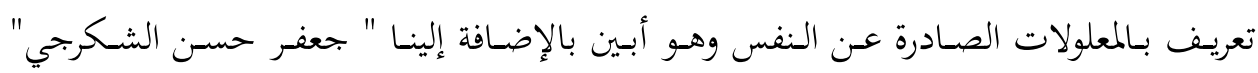

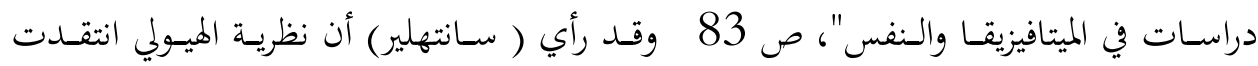


وعيب عليها من طرف الكثير من البحاث ولكن وجهة نظره حولها مختلفة حيث يقول" تلك

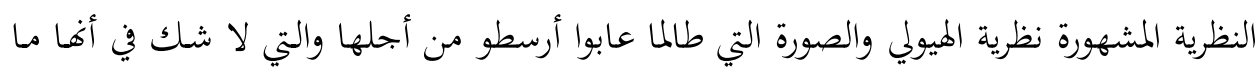
زالت محلاً للانتقاد. أمها أنا فاني أجدها بسيطة وحقة وليس وهـا عيب حتى ولى ولا عيب الغموض ولي ما تؤخذ به أن بها دقة بعض الشيء دون أن تكون مع ذلك سفسطائية ـ فالهيولي والصورة

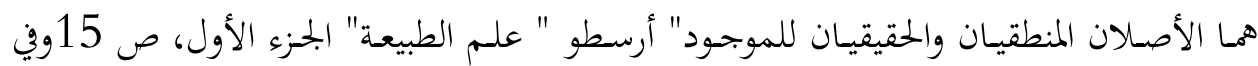
القرن الثامن عشر أعاد" (كويلر ويتر) في بحال توليد النباتات الهجينة التساؤل حول الكيفية التي

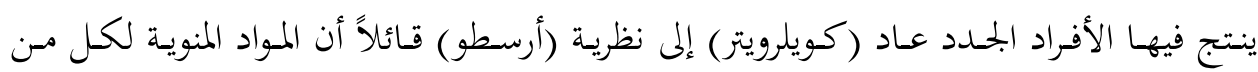

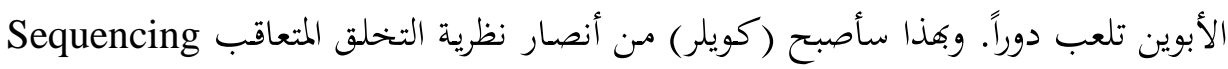

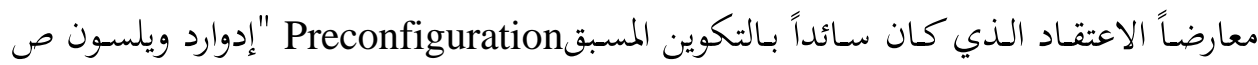
13 تعود نظرية التكوين المسبق إلى (أنتوين فان لووفنهويك) " في هولندا حيث قال " عندما

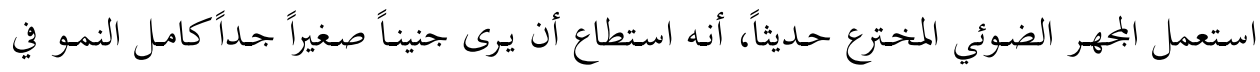
رحم امرأة تطور إلى فرد جديد عندما صار في تماس مع المني، كانت هذه الملاحظة أساس نظرية التكوين المسبق" إدوارد ويلسون ص 13ولكن العلم في تطوره استبعد تلك النظرية. ويمكن القول بأن فلسفة البيولوجيا عند ( أرسطو) تقوم على بحموعة من النظريات منها:

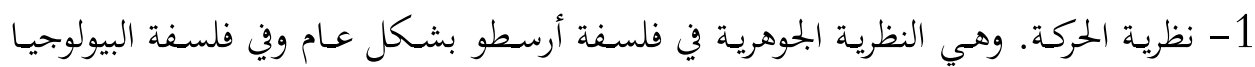
بصورة خاصة.

2- نظرية الهيولي. وهي القائلة بفكرة المادة المكونة. 3- نظرية الصورة. وهي الناتحة عن الهيولي بأشكال متعددة. 4- نظرية العلاقة بين الهيولي والصورة. والتي يخالف فيها تصور استاذه أفلاطون.

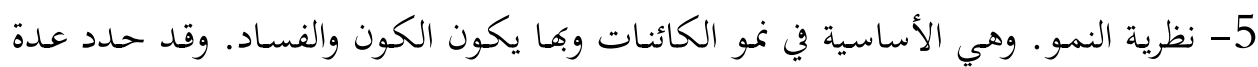
نقاط لفكرة النمو الجسماني منها: أ- " أن كل جزء ما يصير أكبر في عظم ينمو. مثلاً إذاكان من اللحم فإن جزءاً من اللحم ينمو 
ب-أن النمو يكصل بانضمام ما إلى الجسم

ت- يلزم أن الشيء ينمو وأن يبقى معاً.

وفي الواقع حينما شيء يكون أو يبيد مطلقاً فهو لن يبقى البتة. ولكن حين يعاني استحالة أو ئوان

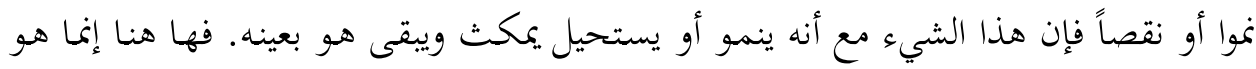
كيف الشيء وحده هو الذي لا يبقى هو هو" أرسطو "الكون والفساد" ص 150 15وبالتأكيد فإن مفهوم النموGrout أيام أرسطو وعلمه ليس كما هو اليوم في البيولوجيا الحديثة التي تحدد

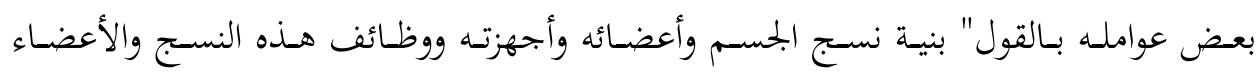

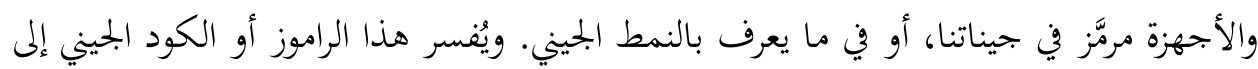

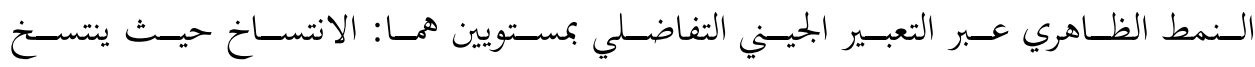
ARN، RNA، ADN،DNA تشكل النمط من الظاهري. ويتم التعبير الجيني التفاضلي في أثناء تكون الفرد ويؤدي إلى تكون

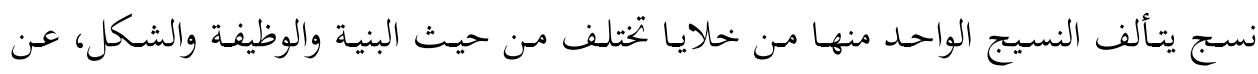
خلايا أي نسيج آخر، في الوقت الذي تبقى فيه الخلايا كافة وين النستج كلها محتوية في نواها

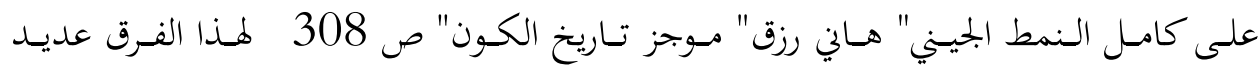

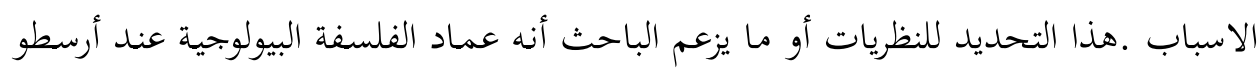

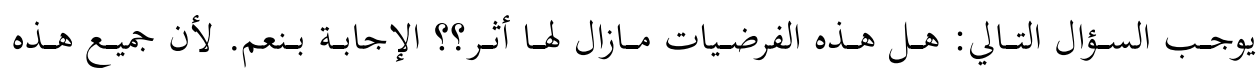
الفرضيات أساسية في دراسة الكائنات التي تحدث عنها أرسطو في فلسفته وهي أيضاً المحاور التي تقوم عليها فلسفة وعلوم البيولوجية الحديثة.

\section{منهج أرسطو الطبيعي Aristotle 's natural approach.}

يميز أرسطو " بمنتهى الجحلاء بين الفروع الاساسية للبحث العلمي : الطبيعيات والعلوم

الرياضية من جهة أولى، والعلوم البيولوجية من الجهة الثانية. وقد كانت الرياضيات تحظى بمكانة

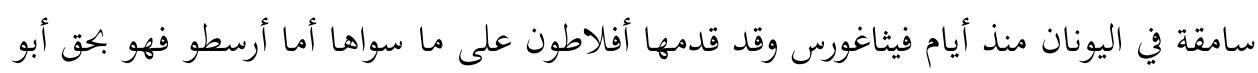

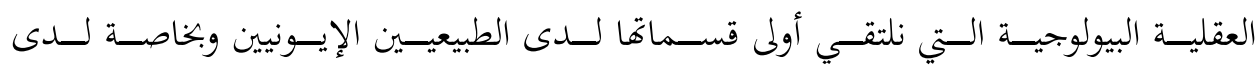


أنكسيماندريس 610 Anaximandre-547 ق. م " جورج طرابيشي" معجم الفلاسفة"

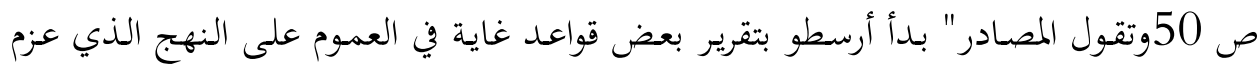

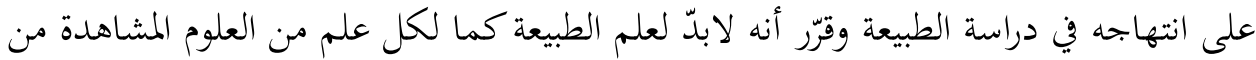

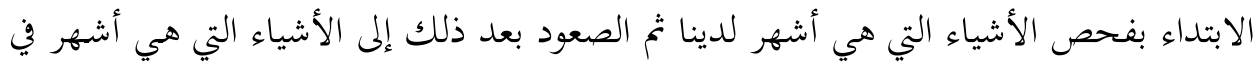

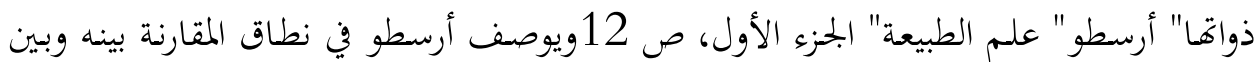

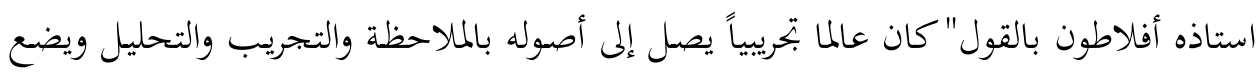

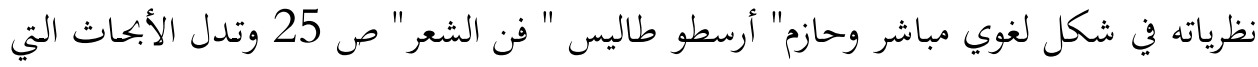

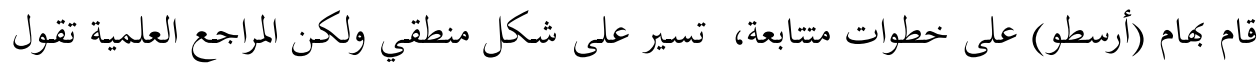

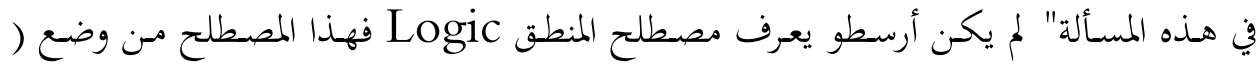

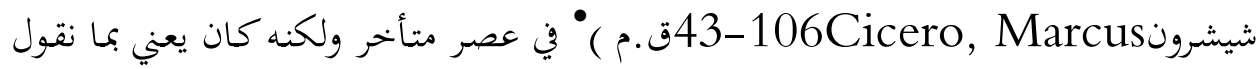
عنده المنطق ( التحليلات) وصناعة التحليل عنده تمر في مـرحلتين: أولى وثانية، فالأولى هي

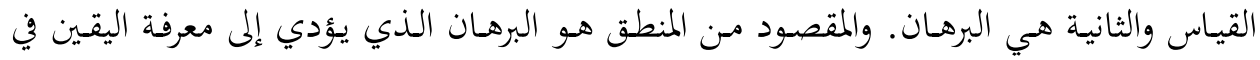

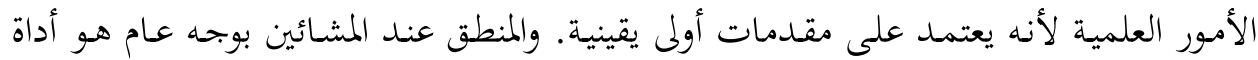

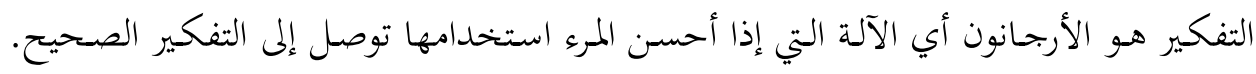

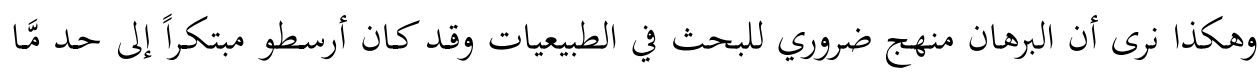

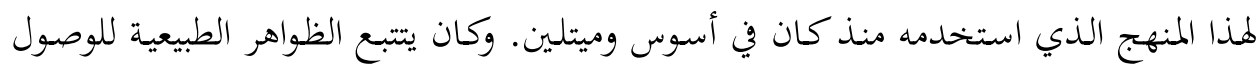

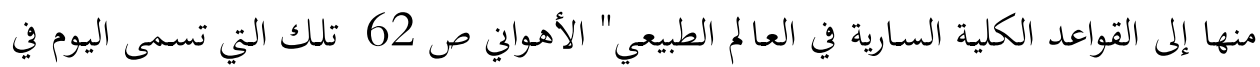

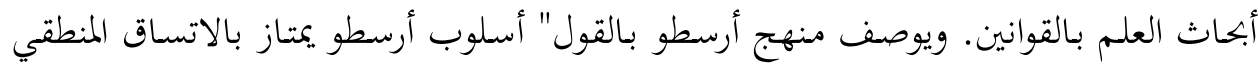

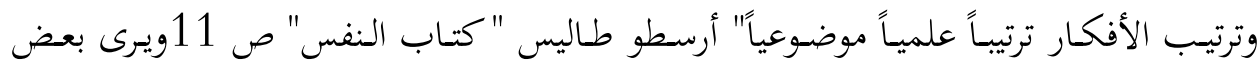

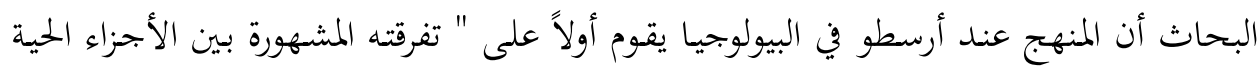

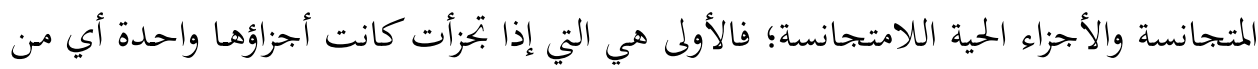

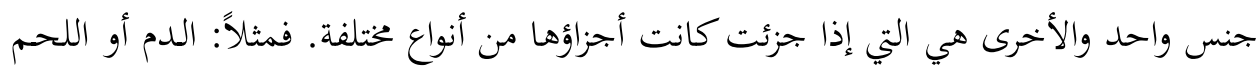

• كاتب وخطيب وفيلسوف لاتيني. 
يُعد متجانساً لأن أي جزء أخذته منه يساوي في الجنس والنوع أي جزء آخر. بينما الوجه مثلاً

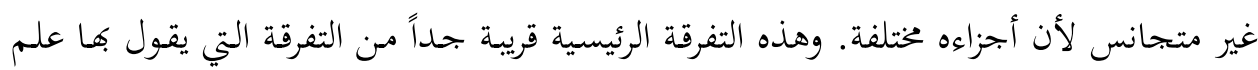

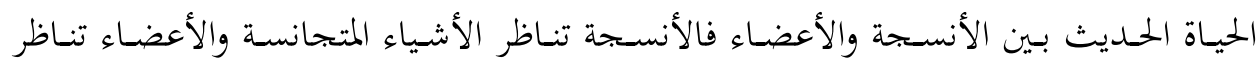
الأشياء اللامتجانسة لأن من خصائص المتعضي اختلاف الأجزاء من حيث النوع مع اتفاقها في أداء وظيفة واحدة ـ و.جذا وضع أرسطو الأساس لتفرقة رئيسة في علم الحياة ونعني بها التفرقة بين علـم التشريح وعلـم وظـائف الأعضـاء"بدوي( أرسطو) ص 230 ويـرى ( أرسطو) أن عـالم الطبيعة عليه أن " يبحث في نوعين من العلل: المادية، والعلل الغائية. مع تأكيده على أن ميدان بحثه الحقيقي هو العلل الغائية. فالطبيعة تضع الغاية دائماً نصب عينيها" Wardman, F.\& Green,J.L,The philosophy of Aristotle p22

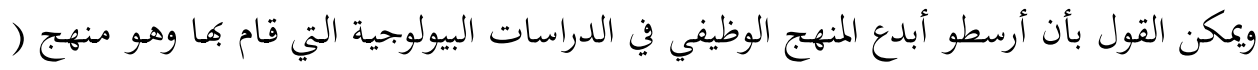
طريقة) التماثل." ويقصد به أتفاق أنواع الحيوان المختلفة في الصورة العامة للوظائف أو للأعضاء

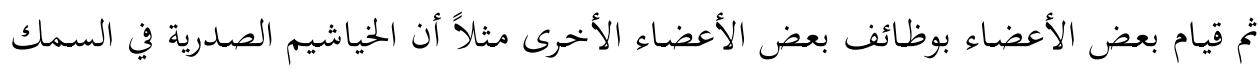
تناظر الرئة في الإنسان والخرطوم في الفيل يناظر اليد في الإنسان. التماثل تناسب في الوظائف

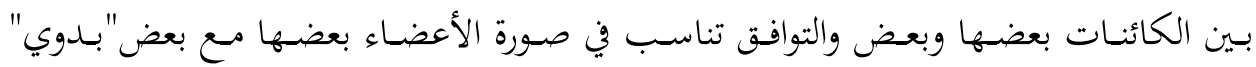
أرسطو" ص 230 ولكن أرسطو لم يقدم تفرقة بين مفهومي التماثل Emmercyity والتوافق Georges Cuvier كما قدمه علماء العلم الحديث مثل (جورج كوفييه . Capability 1769 -1832م ويمكن القول بأن مـنهج ( أرسطو) في دراسته البيولوجية يقوم على مبـدأ الغائية Teleology . والسؤال ماهي الغائية. Teleology الغائية وهي العلة الطبيعية الرابعة عند ( أرسطو) وهي: "المادة، والصورة، والحركة، والغاية. وهذه العلل

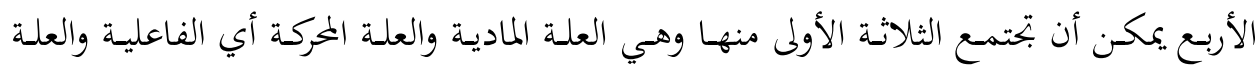
الصورية، في بحموعة واحدة وأما العلة الغائية فهي تنفرد عن العلل السابقة في أها الهدف النهائي للفعل" محمّد على أبوريان، حربي عباس عطيتو" دراسات في الفلسفة القديمة والعصور المعاصرة" 
ص 48 ويفترض أرسطو وجود علل أربع مسؤولة عن كل تغير أو تطور، أول هذه العلل هيَ

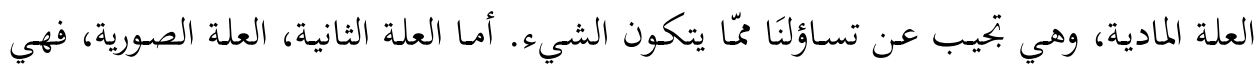
النموذج الذي يتحدد عبره الشيء، فكرة المثال الموجودة في ذهنه عن التمثال مثلا. العلة الفاعلة

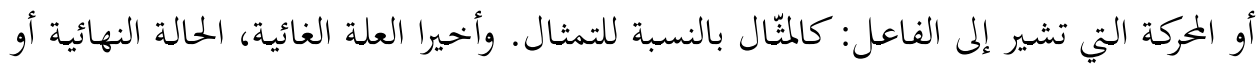
التامة التي خرج من أجلها الشيء من القوة إلى الفعل، وذلك كالصورة النهائية التي يتحول إليها الحجر فيصبح تمثالا. وهذه العلل تتعدد في الشيء الواحد، كما هو موضسح في الصورة، وهي

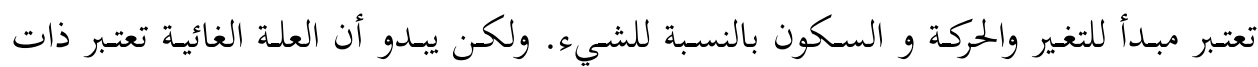

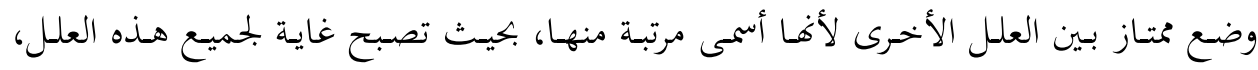
وهكذا يرى أرسطو أن " الغائية " مبدأ أساسي في الطبيعة. هذه الغائية التي تحدث عنها لهات أرسطو منذ الأف السنين يقول بها اليوم بعض البحاث في علم الحياة" لدى تكون البمموعة الشمسية قبل 4.6 مليار عام، ظل المطر يتساقط على سطح الأرض قرابة خمسمائة مليون عام، وتشكل الحسـاء البـدائي. كانـت كل هـذه التحولات تحـدث ( بتأثير مـن القوى التكافؤية واللاتكافؤيـة المسؤولة عن الانتقاء الطبيعي الموجه) لتنقل البنية من الأبسط إلى الأعقد، ومن الأقل إلى الأكثر

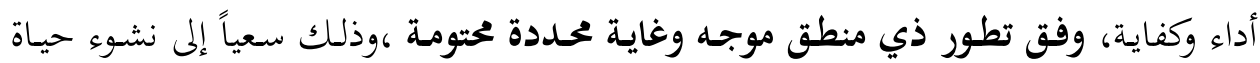

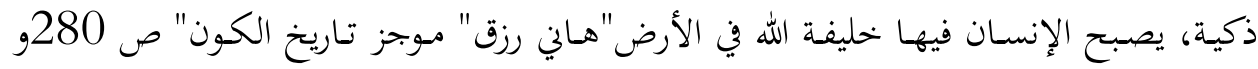

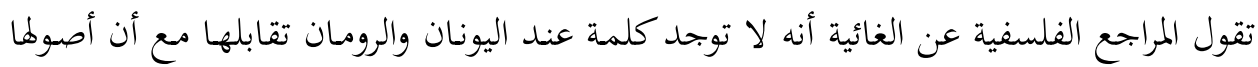

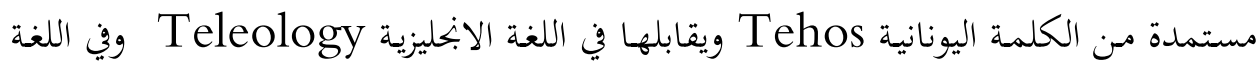
الفرنسية Teleologie وفي اللغـة الألمانيـة Teleologie وفي تعريفها في المعـاجم العلميـة والقواميس الفلسفية توصف بأغها " لا تخرج عن كوفا فرعاً من دراسة فلسفية يعالج غايات أو

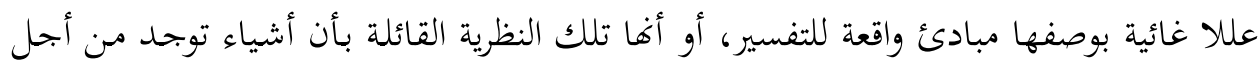
غرض Purpose أو لغاية End والمعنى الأكثر استعمالاً لكلمة الغائية يرتبط بالسؤال عن الأغراض Purposes أقصد الأغراض التي وجدت من أجلها الأشياء ويتضح من هذا التعريف

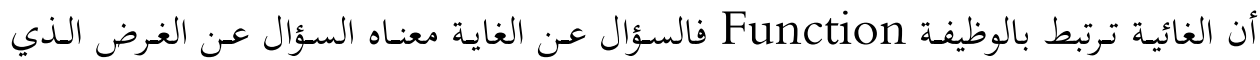


Baldin J.M:Dictionary of وجـد مـن أجلـه أو سـؤال عـن الوظيفـة التي يؤديهـا philosophy \&psychologypp.664.667 وقد قسم (أرسطو) النفس التي هي محور دراسته ئه في البيولوجيـا إلى" نفس نباتيـة أو قوة غاذيـة، ونفسس حاسـة، ونفسس عاقلة. وينظر إلى أقسـام

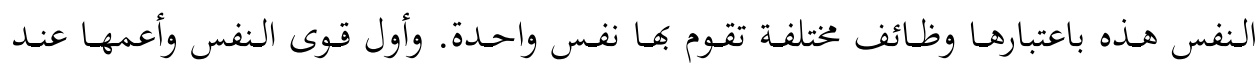

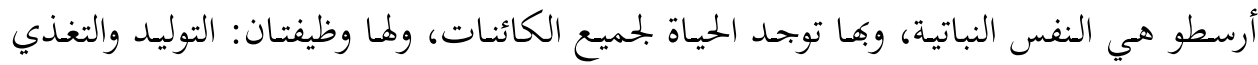
وهي القوة الوحيدة الموجودة في النبات دون الحس والعقل، ولا يوجد الحس والعقل بدوفها في الحيوان الأعجم والإنسان" جعفر حسن الشكرجي" دراسات في الميتافيزيقا والنفس " ص ص 83 والنفس النباتية " أو القوة الغاذية تكون أقرب إلى الوظائف الطبيعية لكل كائن حي كامل وهو

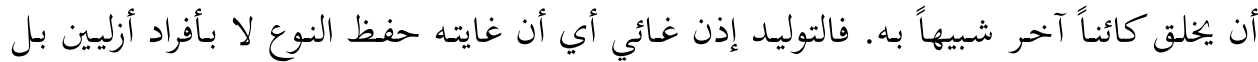

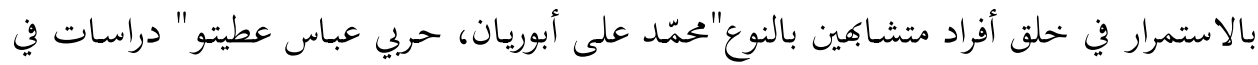

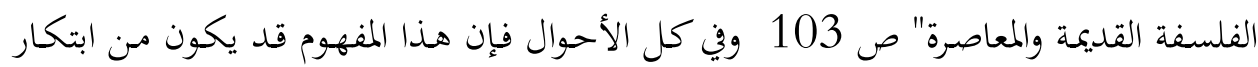
الفيلسوف ( أرسطو) حيث جاء في دراساته البيولوجية في قسم الكائنات الحية. وهي في مذهبه

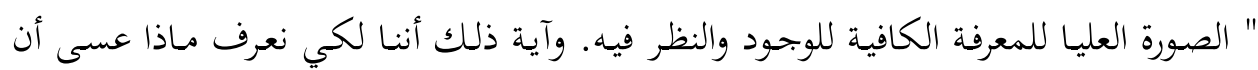
يكون الشيء معناه علينا أن نعرف من أجل أي شيء يكون ومعرفة غاية الشيء معناه معرفة

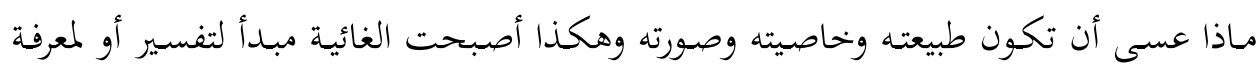
الأشياء" Wardman, F.\& Green,J.L,The philosophy of Aristotle,. Pp. 27.28

$$
\text { وهذا يتضح عند ( أرسطو ) من خلال منهجه. }
$$

آراء في الغائية Opinions in the teleological. هناك عدة أراء في الغائية منها: المذهب المثالي وينقسم إلى شعبتين: 1- بحموعـة ترى أن الاشياء الطبيعيـة تـدين بوجودهـا الغائي "لعليـة وفقـاً لقوانين ديناميكيـة،

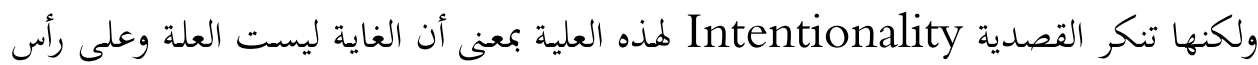


هذه الطائفة ( ديمقريطس 341-360Democritus

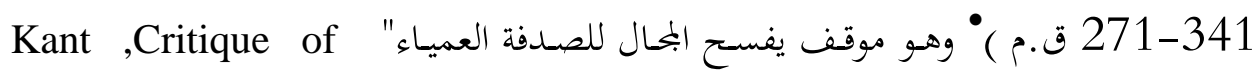
Judgement, the second part, Critique of teleological Judgement an English trans. By Meredith,J.C,Oxford,1928.p 45 وذهب ( ديمقريطس) إلى فكرة الضرورة التي تنظم الأشياء وأنه ليست هناك غاية أو هدف في

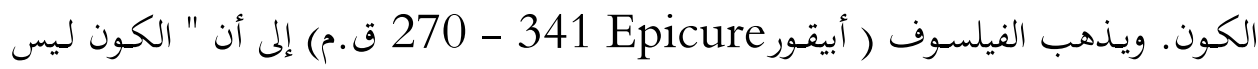

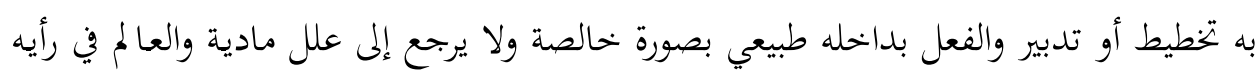

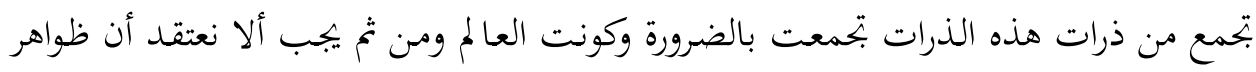

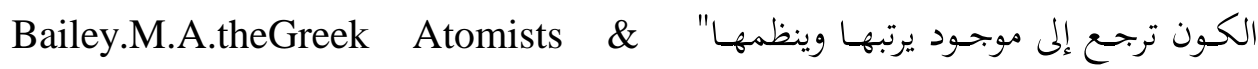
Ebicuruss Pp.363-370

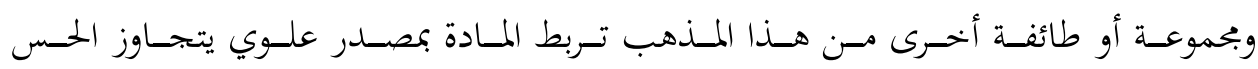

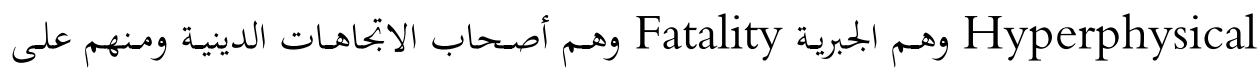

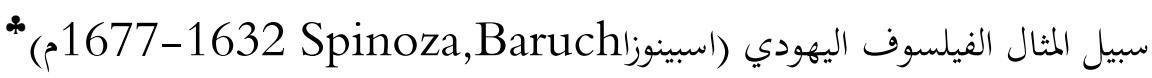

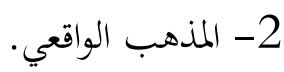

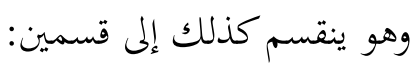
1- أصحاب النزعة الحيوية Hylozism يرون أن غائية الكائنات الحية هي بمثابة قوة كامنه

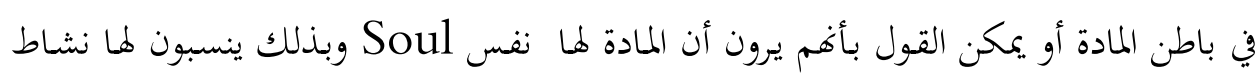

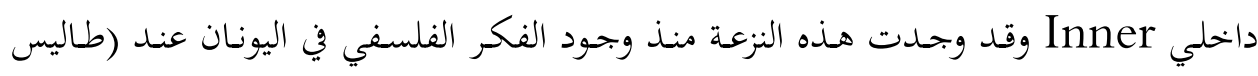

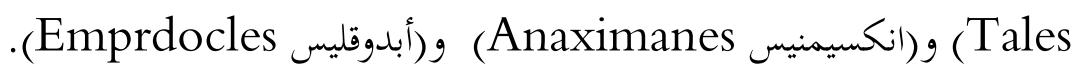
2- مذهب المؤلة Theism وهذا المذهب يرى أن مصدر الحياة كامن في مصدر علوي فائق للطبيعة وهو يعبر عن فلاسفة اللاهوت.

" فيلسوف يوناني ولد في ابديرايعد اكبر ممتل للدذب الذربي القيم ومؤسس نظرية الجزء الذي لا يتجزأ.

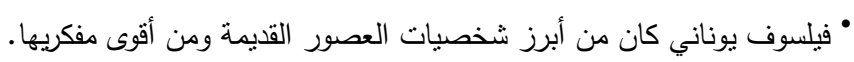
" فيلسوف مادي هولندي طردته الجالية اليهودية بامستردام من مجمع اليهود. من مؤلفاته: البحث اللاهوتي السياسي

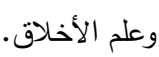


أسس التفسير الطبيعي عند أرسطو The foundations of natural interpretation .at Aristotle

يقوم التفسير الطبيعي عند ( أرسطو) على ثلاث مبادئ وضعها ولم يشتقها من الوجود التجريبي

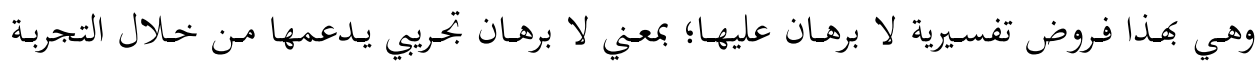

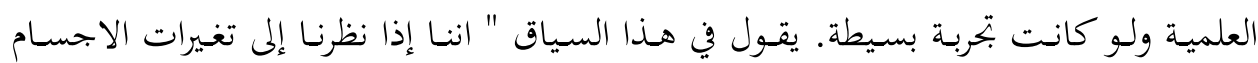
الطبيعية وجحدنا أنه لكي يتم أي تغير وهو يعني التغير الجوهري الذي يلحق الجوهر لا الأعراض

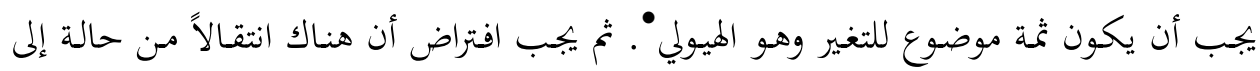

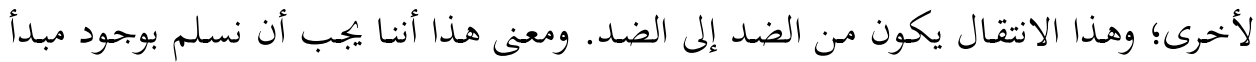

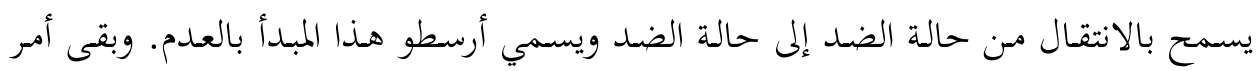
هام وهو هذا الشيء الذي يتم به التغير والذي ينتقل من الضد إلى الضد هذا المبدأ الثالث هو

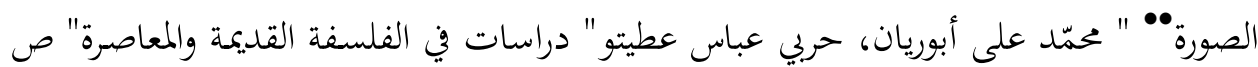
40 وتشير المراجع إلى أن ( أرسطو) يؤكد " أن صورة النباتات هي التغذية وصورة الحيوانات هي عي دروسي

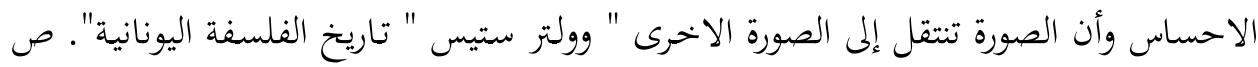
273 وعلى ذلك فإن أسس التفسير الطبيعي عند أرسطو هي: 1- الهيولي وهي موضوع التغير 2- العدم وهو نقطة فاية صورة وبداية صورة أخرى. 3- الصورة وهي كمال أول للهيولي

His Works are in biology مؤلفاته في البيولوجيا ألف أرسطو عديد الكتب في البيولوجيا منها:

• موضوع غير معين إذ أنها ليست مادة مكتملة، وهي أيضاً ليست ماهية أو كمية أو كيفية، هي قوة صرفة لا بمكن

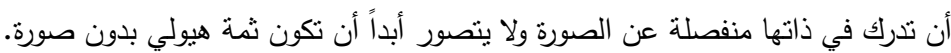

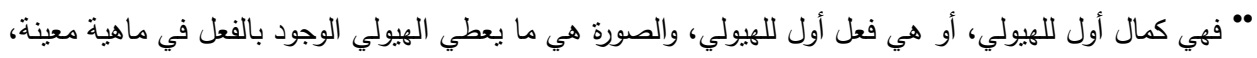

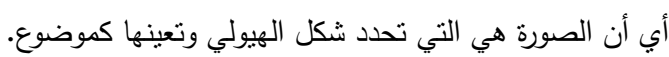




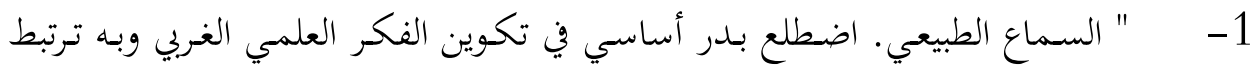

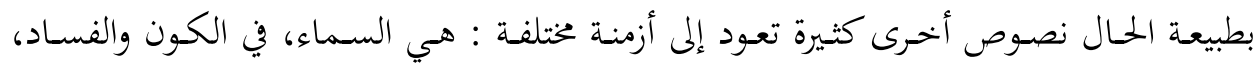
الآثار العلوية، " جورج طرابيشي" معجم الفلاسفة" ص 50

$$
\text { 3- 2- كتاب الطبيعة }
$$

4- كتاب الكون والفساد. وهو أحد مصادر هذا البحث كاب السماء

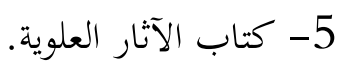

6- كتاب علم الطبيعة. الجزء الأول، الجزء الثاني. وهو من مصادر هذا البحث البح العلية

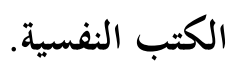

1- كتاب النفس. من مصادر هذا البحث. " يعثل بالنسبة للفلسفة والعلوم الأرسطية عقد لها

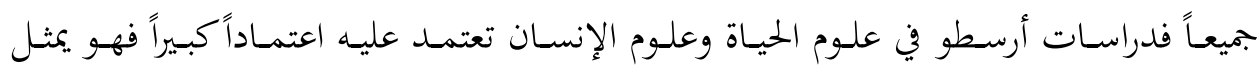

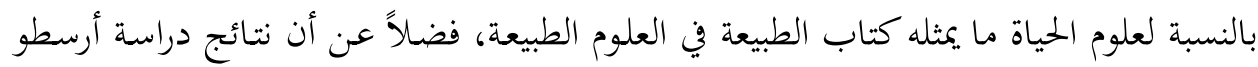

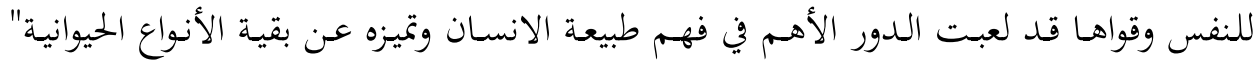
أرسطو طاليس "كتاب النفس" ص 12

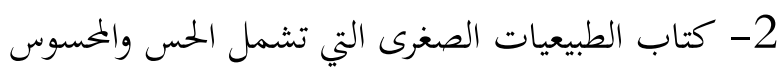

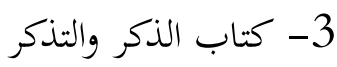

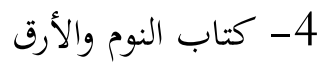
كتب تبحث في الحيوان. يشير الجاحظ في كتابه الحيوان إلى أن أرسطو قد كتب في علم الحيوان

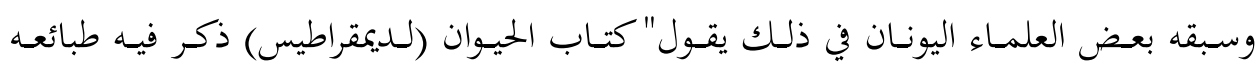

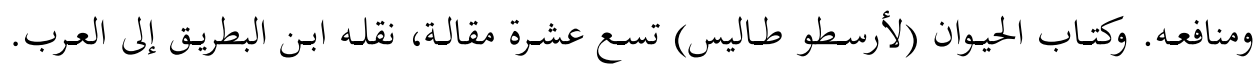

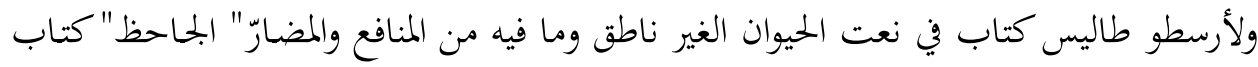

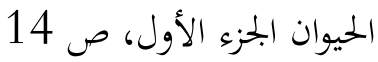




$$
\begin{aligned}
& \text { كتب أرسطوفي علم الحيوان . } \\
& \text { 1- تاريخ الحيوان } \\
& \text { 2- مشي الحيوان } \\
& \text { 3- حركة الحيوان }
\end{aligned}
$$

ويرى بعض البحاث أن هذه الكتب تدخل في سياق التاريخ الطبيعي عند أرسطو " مؤلفاته في

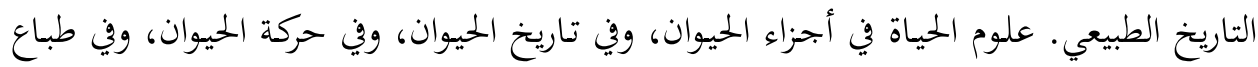
الحيوان" أرسطو طاليس "كتاب النفس "ص 11 وكان كتاب الحيوان لأرسطو من مراجع كتاب الحيوان للجاحظ " وقد نقل عنه الجحاحظ نصوصاً ليست من الكثرة بمكان ولكنها من القيمة والنَّفاسة بمكان عظيم" الجاحظ "كتاب الحيوان" الجزءء الأول، ص 20

\section{مصادره في علم الحيوان.Sources in Zoology.}

هنا يمكن القول بأن مساعدة (الاسكندر المقدوني

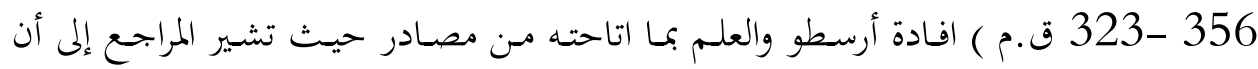

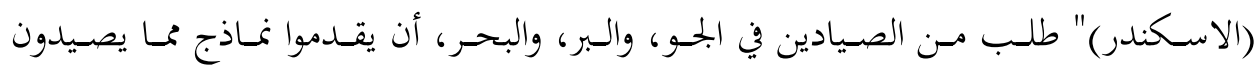

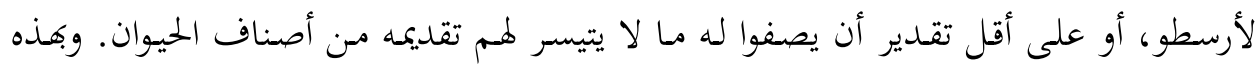

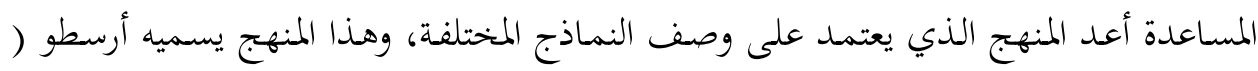
التاريخ الطبيعي) وفيمـا يختص بـالحيوان يسميه تاريخ الحيوان. ويقصد بذلك تسجيل وأصنافه

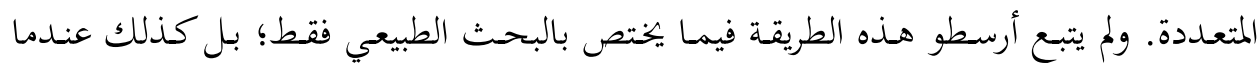

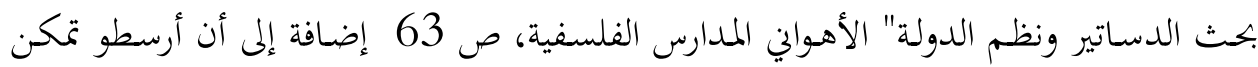

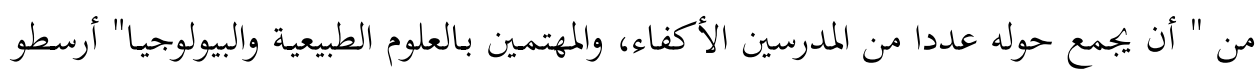
طاليس " فن الشعر" صن 17 Aristotle's Influence in the Philosophy of أثر أرسطو في فلسفة البيولوجيا

.Biology بعد وفاة ( أرسطو) تولى رئاسة المدرسة ( ثاوفراسطس Theophrastus) ثمانية وثلاثين عاماً

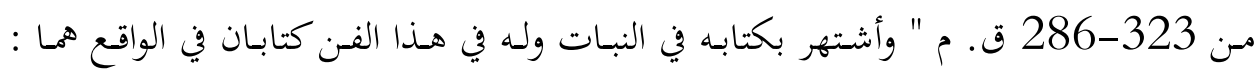


تاريخ النبات، وعلل النبات. ظلا عمدة هذا العلم في الزمن القديم والعصر الوسيط. ثم تولى

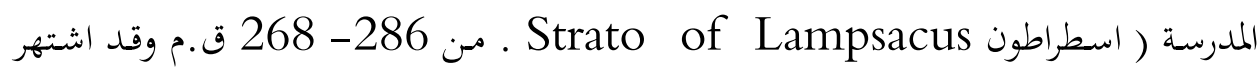
باسم اسطراطون الطبيعي بسبب انقطاعه لبحثث الطبيعة وقد علم ( بطليموس فيلاديلفوس (PtolemyPhiladelphus الاسكندر لأرسطو" الأهواني ص 65 و ويلاحظ عديد البحاث على مـذهب ( أرسطو) في

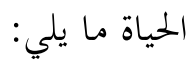
1- " مذهب أرسطو في الحياة بوجه عام مذهب حيوي إلى حد كبير 2- وأنه ينفي كثيراً أو دائماً كل تفسير فزيائي كيمياوي للظواهر الخاصة بامي بالحياة

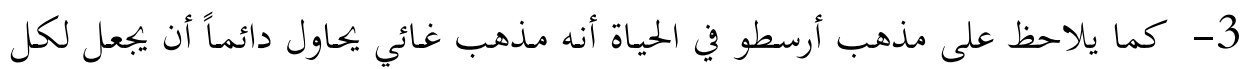
عضو غاية ولكل كائن في الحياة غاية 4- وعن طريق فكرة الغائية بجده دائماً يحاول أن يفسر الأوضاع والوظائف الخاصة بأعضاء الكائن الحي" بدوي " أرسطو" ص 235 The centerpiece of Aristotle's natural محاور فلسـفة أرسطو الطبيعـة يمكن استنتاج محاور فلسفة الطبيعية عند أرسطو في ما يلي :philosophy 1- تقوم على منهج محدد كما أشار البحث. ويمكن وصفه بالبحث النقدي لأنه يدكر الفكرة أو التفسير عند فيلسوف آخر ويقوم بتصحيحه ونقده. 2- أنها منتوجات الطبيعة ذاتا. وتفاعلاتما. 34- - ليست من صنع البشر 5- ممكن للبشر العلماء منهم أجرى بعض التحويرات عليها. 6- أها فلسفة شاملة للكائنات وكذلك التفاعلات الطبيعية مثل البرق والرعد. 
من خلال هذا البحث، يمكن القول بأن (أرسطو طاليس) كان عالماً ومهتماً بعلوم الحياة منذ

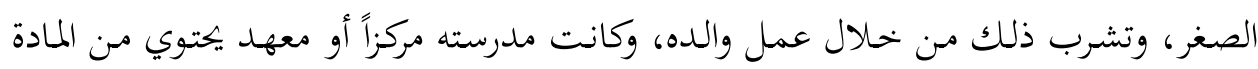
العلمية ما يدلل على ذلك كما ذكرهذا البحث. كما قدم نظريات علمية في الفلسفة الطبيعة، ولته

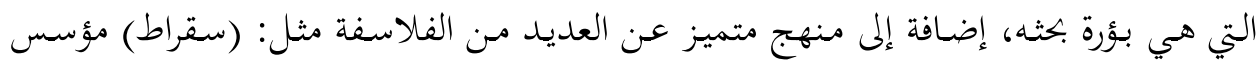

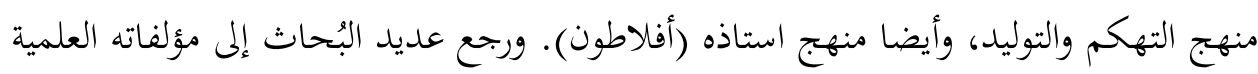

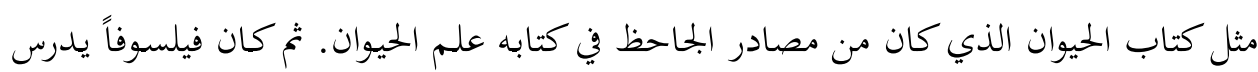

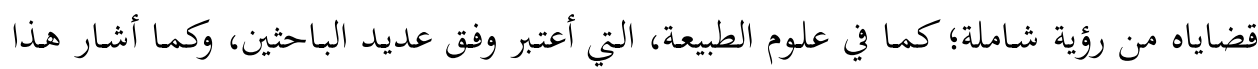

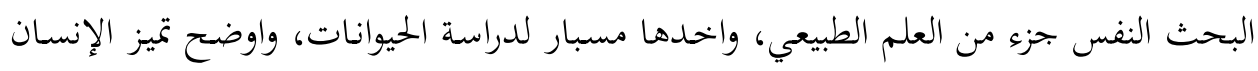

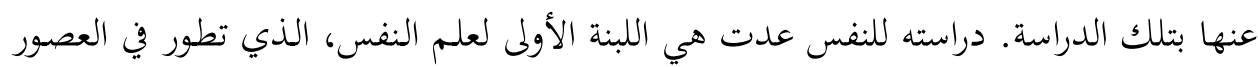

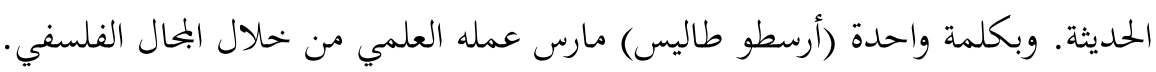




\section{قائمة المصادر والمراجع.}

المصادر.

$$
\text { 1 - أرسطو طاليس " الطبيعة" جزئيين. }
$$

أ- أرسطو "علم الطبيعة لأرسطو طـاليس" ترجمة، أحمــ لطفي السيد، الهيئة المصرية العامـة

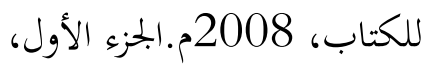
ب-أرسطو طاليس " الطبيعة " ترجمة، إسحق بن حنين، الدار القومية للطباعة والنشر، القاهرة،

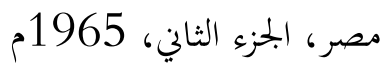

2- أرسطو طاليس" فن الشعر" ترجمة، ابراهيم حمادة، مكتبة الانجلو المصرية، القاهرة، مصر، .

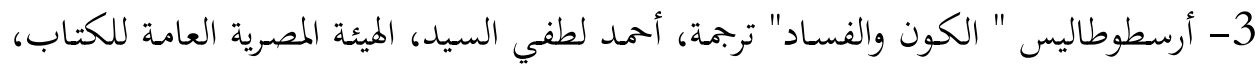
القاهرة، مصر 4- أرسطو طاليس "كتاب النفس" ترجمة، أحمد فؤاد الاهواني، الطبعة الثانية، المركز القومي للترجمة، القاهرة، مصر، 2015م. المراجع.

1- أحمد فؤاد الاهواني" المدارس الفلسفية" المكتبة الثقافية، القاهرة، مصر، 1965م. 2- الجـاحظ" كتـاب الحيوان" تحقيـق، عبدالسـلام محمـد هـارون، الطبعـة الثانيـة، شـكة مكتبـة ومطبعة مصطفى البابي، القاهرة، مصر، الجزء الأول.

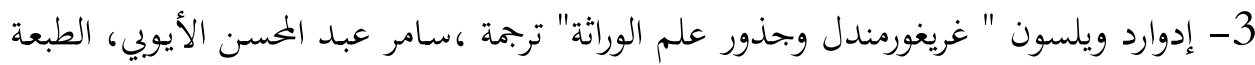
العربية الأولى، مكتبة العبيكان، الرياض، السعودية، 2004

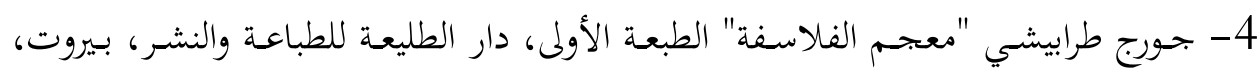
لبنان، 1987م 5- جعفر حسن الشكرجي" دراسات في الميتافيزيقا والنفس" الطبعة الأولى، مكتبة الأندلس،

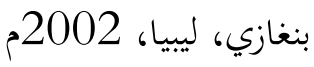


6- رنا مزيك" علم الآثار العلوية في الحضارات القديمة وعند العلماء العرب" منشورات الهيئة

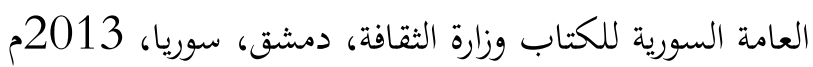

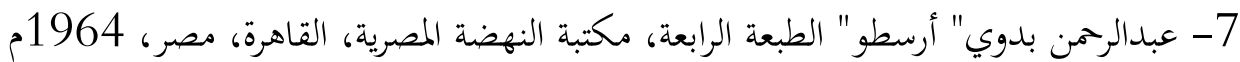

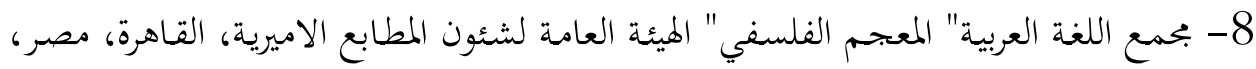
1983

9- م.روزنتال، ب يودين" الموسوعة الفلسفية" ترجمة، سمير كرم، الطبعة السادسة، دار الطليعة،

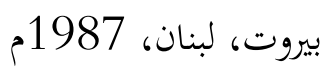

10- منير على الجنزوري" نحن والعلوم البيولوجية" دار المعارف، القاهرة، مصر، الجزء الأول

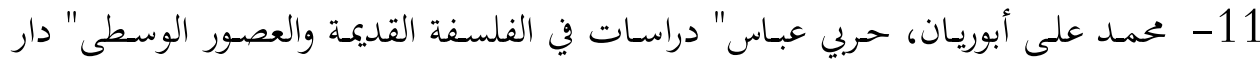
المعرفة الجحامعية، الاسكندرية، مصر، 1999م 12- وولتر ستيس" تاريخ الفلسفة اليونانية" ترجمة ، بحاهد عبد المنعم بجاهد، دار الثقافة للنشر

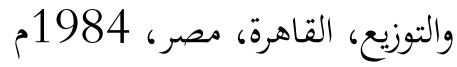
13- هاني رزق" موجز تاريخ الكون" الطبعة الأولى، دار الفكر، دمشق، سوريا، 2003م المراجع الأجنبية.

1- Sylvia S. Mader " biology" second edition, printed in the united States of American 1987

2- Wardman, F.\& Green,J.L,The philosophy of Aristotle ,New American,Library, 1963

3- Baldin, J.M:Dictionary of philosophy \&psychology v. 11.Gloucester,peter Smith 1966

4- Kant ,Critique of Judgement, the second part, Critique of teleological Judgement , an English trans. By Meredith,J.C,Oxford,1928 Bailey.M.A.the Greek Atomists \& Ebicurus. Oxford 1928. 